The University of Maine

DigitalCommons@UMaine

Marine Sciences Faculty Scholarship

School of Marine Sciences

5-1-2019

\title{
Inversion of inherent optical properties in optically complex waters using sentinel-3A/OLCI images: A case study using China's three largest freshwater lakes
}

\author{
Kun Xue \\ Nanjing Institute of Geography and Limnology Chinese Academy of Sciences \\ Ronghua Ma \\ Nanjing Institute of Geography and Limnology Chinese Academy of Sciences \\ Hongtao Duan \\ Nanjing Institute of Geography and Limnology Chinese Academy of Sciences \\ Ming Shen \\ Nanjing Institute of Geography and Limnology Chinese Academy of Sciences \\ Emmanuel Boss \\ University of Maine, emmanuel.boss@maine.edu
}

See next page for additional authors

Follow this and additional works at: https://digitalcommons.library.umaine.edu/sms_facpub

Part of the Oceanography and Atmospheric Sciences and Meteorology Commons

\section{Repository Citation}

Xue, Kun; Ma, Ronghua; Duan, Hongtao; Shen, Ming; Boss, Emmanuel; and Cao, Zhigang, "Inversion of inherent optical properties in optically complex waters using sentinel-3A/OLCl images: A case study using China's three largest freshwater lakes" (2019). Marine Sciences Faculty Scholarship. 227.

https://digitalcommons.library.umaine.edu/sms_facpub/227

This Article is brought to you for free and open access by DigitalCommons@UMaine. It has been accepted for inclusion in Marine Sciences Faculty Scholarship by an authorized administrator of DigitalCommons@UMaine. For more information, please contact um.library.technical.services@maine.edu. 
Authors

Kun Xue, Ronghua Ma, Hongtao Duan, Ming Shen, Emmanuel Boss, and Zhigang Cao

This article is available at DigitalCommons@UMaine: https://digitalcommons.library.umaine.edu/sms_facpub/227 


\title{
Inversion of inherent optical properties in optically complex waters using sentinel-3A/OLCI images: A case study using China's three largest freshwater lakes
}

\author{
Kun Xue ${ }^{\mathrm{a}}$, Ronghua Ma ${ }^{\mathrm{a}, *}$, Hongtao Duan $^{\mathrm{a}}$, Ming Shen ${ }^{\mathrm{a}, \mathrm{b}}$, Emmanuel Boss ${ }^{\mathrm{c}}$, Zhigang Cao ${ }^{\mathrm{a}, \mathrm{b}}$ \\ ${ }^{a}$ Key Laboratory of Watershed Geographic Sciences, Nanjing Institute of Geography and Limnology, Chinese Academy of Sciences, 73 East Beijing Road, Nanjing 210008 , \\ China \\ ${ }^{\mathrm{b}}$ University of Chinese Academy of Sciences, Beijing 100049, China \\ ${ }^{\mathrm{c}}$ School of Marine Sciences, University of Maine, Orono, ME 04469, USA
}

\section{A R T I C L E I N F O}

\section{Keywords:}

Inherent optical properties (IOPs)

Remote Sensing reflectance

Quasi-analytical algorithm (QAA)

Sentinel-3A/OLCI

Quantified uncertainty

\begin{abstract}
A B S T R A C T
Inherent optical properties (IOPs) play an important role in underwater light field, and are difficult to estimate accurately using satellite data in optically complex waters. To study water quality in appropriate temporal and spatial scales, it is necessary to develop methods to obtain IOPs form space-based observation with quantified uncertainties. Field-measured IOP data $(\mathrm{N}=405)$ were collected from 17 surveys between 2011 and 2017 in the three major largest freshwater lakes of China (Lake Chaohu, Lake Taihu, and Lake Hongze) in the lower reaches of the Yangtze River and Huai River (LYHR). Here we provide a case-study on how to use in-situ observation of IOPs to devise an improved algorithm for retrieval of IOPs. We then apply this algorithm to observation with Sentinel-3A OLCI (Ocean and Land Colour Instrument, corrected with our improved AC scheme), and use in-situ data to show that the algorithm performs better than the standard OLCI IOP product. We use the satellite derived products to study the spatial and seasonal distributions of IOPs and concentrations of optically active constituents in these three lakes, including chlorophyll- $a$ (Chla) and suspended particulate matter (SPM), using all cloud-free OLCI images (115 scenes) over the lakes in the LYHR basin in 2017. Our study provides a strategy for using local and remote observations to obtain important water quality parameters necessary to manage resources such as reservoirs, lakes and coastal waters.
\end{abstract}

\section{Introduction}

Inherent optical properties (IOPs; refer to Table 1 for symbols and acronyms), namely, absorption $(a(\lambda))$ and backscattering $\left(b_{b}(\lambda)\right)$ coefficients of water and its constituents, are the most important intermediate variables for water color remote sensing and link between satellite signals and optically active constituents (OACs), such as suspended sediments, phytoplankton and colored dissolved materials. They are related to water quality and biogeochemistry and determine the subsurface spectrum and distribution of radiance (light field) (Gordon et al., 1975; Morel and Prieur, 1977). IOPs are generally used to estimate OACs (e.g. Carder et al., 1999; Mishra et al., 2013), the diffuse attenuation coefficient of downwelling irradiance at $490 \mathrm{~nm}$ ( $K_{\mathrm{d}}(490)$ ) (Kirk, 1984; Lee, 2005; Mishra et al., 2013), as well as estimate phytoplankton pigment concentration (Lee et al., 2011; Mitchell and Cunningham, 2015), and carbon pools (Kutser et al., 2005; Stramski et al., 1999; Zhu et al., 2011). However, traditional measurements of IOPs such as those involving laboratory analysis and field instruments provide insufficient spatial information of IOPs, especially in inland lakes with significant optical variations in space and time. Satellite ocean color remote sensing provides estimation of IOPs and OACs at high spatial and temporal resolution through inversion algorithms from radiance measured at the top-of-the-atmosphere.

Significant progress in IOP inversion algorithms has been achieved but mainly in oceanic and coastal waters. Among these existing algorithms, empirical algorithms are popular using multiple-band regression to relate IOPs to remote sensing reflectance $\left(R_{r s}\right)$. However, their application is limited due to the uncorrelated and dynamic variability of optical properties across different types of water bodies (Vandermeulen et al., 2015). Semi-analytical inversion algorithms (SAAs), based on combination of radiative transfer equations and some empirical methods, perform better than the empirical algorithms over water bodies that exhibit large variations in properties (Li et al., 2013). Several solution methods of SAAs have been developed to derive the

\footnotetext{
* Corresponding author.

E-mail address: rhma@niglas.ac.cn (R. Ma).
} 
Table 1

Acronyms, abbreviations, and symbols.

\begin{tabular}{|c|c|c|}
\hline \multicolumn{3}{|c|}{ Acronyms and abbreviations } \\
\hline AOPs & & Apparent optical properties \\
\hline $\mathrm{CDOM}$ & & Colored dissolved organic matter \\
\hline IOPs & & Inherent optical properties \\
\hline NAP & & Non-algal particulates \\
\hline OACs & & Optically active constituents \\
\hline SPIM & & Suspended particulate inorganic matter \\
\hline SPM & & Suspended particulate matter \\
\hline SPOM & & Suspended particulate organic matter \\
\hline NOMAD & & NASA bio-optical marine algorithm dataset \\
\hline \multicolumn{3}{|l|}{ Symbols } \\
\hline$a(\lambda)$ & \multicolumn{2}{|c|}{ Total absorption coefficient $\left(\mathrm{m}^{-1}\right)$ at wavelength $(\lambda)$} \\
\hline$a_{d}(\lambda)$ & \multicolumn{2}{|c|}{ Absorption by NAP $\left(\mathrm{m}^{-1}\right)$ at wavelength $(\lambda)$} \\
\hline$a_{d g}(\lambda)$ & \multicolumn{2}{|c|}{ Absorption by NAP and CDOM $\left(\mathrm{m}^{-1}\right)$ at wavelength $(\lambda)$} \\
\hline$a_{g}(\lambda)$ & \multicolumn{2}{|c|}{ Absorption by $\mathrm{CDOM}\left(\mathrm{m}^{-1}\right)$ at wavelength $(\lambda)$} \\
\hline$a_{n w}(\lambda)$ & \multicolumn{2}{|c|}{$\begin{array}{l}\text { Total non-water absorption }\left(\mathrm{m}^{-1}\right) \text { at wavelength }(\lambda), a_{n w}(\lambda)=a(\lambda) \text { - } \\
a_{w}(\lambda)\end{array}$} \\
\hline$a_{p}(\lambda)$ & \multicolumn{2}{|c|}{ Absorption by NAP and phytoplankton $\left(\mathrm{m}^{-1}\right)$ at wavelength $(\lambda)$} \\
\hline$a_{p h}(\lambda)$ & \multicolumn{2}{|c|}{ Absorption by phytoplankton $\left(\mathrm{m}^{-1}\right)$ at wavelength $(\lambda)$} \\
\hline$a_{w}(\lambda)$ & \multicolumn{2}{|c|}{ Absorption by pure water $\left(\mathrm{m}^{-1}\right)$ at wavelength $(\lambda)$} \\
\hline$b_{b}(\lambda)$ & \multicolumn{2}{|c|}{ Total backscattering coefficient $\left(\mathrm{m}^{-1}\right)$ at wavelength $(\lambda)$} \\
\hline$b_{b p}(\lambda)$ & \multicolumn{2}{|c|}{ Backscattering coefficients of particulate $\left(\mathrm{m}^{-1}\right)$ at wavelength $(\lambda)$} \\
\hline$b_{b w}(\lambda)$ & \multicolumn{2}{|c|}{ Backscattering coefficients of pure water $\left(\mathrm{m}^{-1}\right)$ at wavelength $(\lambda)$} \\
\hline$r_{r s}$ & \multicolumn{2}{|c|}{ Remote sensing reflectance just below the water surface $\left(\mathrm{sr}^{-1}\right)$} \\
\hline$R_{r s}$ & \multicolumn{2}{|c|}{ Remote sensing reflectance $\left(\mathrm{sr}^{-1}\right)$} \\
\hline$S_{d}$ & \multicolumn{2}{|c|}{ Spectral slope of $a_{d}$ spectrum (nm ${ }^{-1}$ ) } \\
\hline$S_{d g}$ & \multicolumn{2}{|c|}{ Spectral slope of $a_{d g}$ spectrum $\left(\mathrm{nm}^{-1}\right)$} \\
\hline$S_{g}$ & \multicolumn{2}{|c|}{ Spectral slope of $a_{g}$ spectrum $\left(\mathrm{nm}^{-1}\right)$} \\
\hline
\end{tabular}

IOPs, including the Garver-Siegel-Maritorena algorithm (Garver and Siegel, 1997; Maritorena and Siegel, 2005), H-L algorithm (Hoge and Lyon, 2005), quasi-analytical algorithm (QAA) (Lee et al., 2002; Lee et al., 2009), bulk inversion (Loisel and Stramski, 2000; Loisel et al., 2018), and ensemble inversion (Brando et al., 2012; Moore et al., 2009; Vantrepotte et al., 2012). Inevitably, these algorithms typically carry assumptions about outputs (Gallegos and Neale, 2002; Schofield et al., 2004), the use of ancillary input data (Dong et al., 2013; Mitchell et al., 2014), and region-specific or instrument-specific parameterizations (Schofield et al., 2004; Zheng et al., 2015). However, no single version of IOP inversion model provides consistent and optimum performance for estimation of both total and component IOPs across the range of visible wavelengths and different oceanic regions (Zheng et al., 2014).

As one of the widely used algorithms for ocean color applications, QAA has also been used as one of the default models to process satellite ocean color data in NASA's SeaWiFS Data Analysis System software (SeaDAS) (Zheng et al., 2014). The QAA scheme does not require the pre-defined spectral shape of phytoplankton absorption $\left(a_{p h}(\lambda)\right)$ or colored dissolved organic matter (CDOM) plus non-algal particulate matter (NAP) absorption $\left(a_{d g}(\lambda)\right)$. In addition, no residual difference exists between the input and output $R_{r s}(\lambda)$ at the wavelengths used in the algorithm (Werdell et al., 2018). QAA and QAA-based algorithms first determine $a(\lambda)$ and $b_{b p}(\lambda)$, and then decompose $a(\lambda)$ into their component parts using different methods. To improve the accuracy of the algorithm, most studies mainly focus on the total absorption, $a(\lambda)$ (e.g. Le et al., 2009; Li et al., 2013), the derivation of $a_{p h}(\lambda)$ and $a_{d g}(\lambda)$, or one specific part which dominates in the water, such as $a_{g}(\lambda)$ (e.g. Kutser et al., 2005; Mouw et al., 2013; Zhu et al., 2011). Specifically, some expressions of QAA in terms of deriving and decomposing $a(\lambda)$, such as reference wavelength of $a(\lambda)$ at 550 or $670 \mathrm{~nm}$ and decomposition of $a(\lambda)$ using 412 and $443 \mathrm{~nm}$, do not work in turbid inland waters (Dong et al., 2013; Le et al., 2009). Limitations also exist when linking $a_{d g}(\lambda)$ to bio-optical parameters, since NAP and CDOM originate from different sources. However, separation of $a_{d}(\lambda)$ and $a_{g}(\lambda)$ from $a_{d g}(\lambda)$ remains a challenge due to their similar spectral shapes (Zheng et al., 2015).
The lower reaches of the Yangtze River and Huai River (LYHR) is densely populated with $\sim 137$ million people, economically prosperous (GDP 1.4 trillion dollars in 2017), and supports the commercial fishing industry, agricultural production, drinking water resources, as well as tourism and recreation activities. Notably, the LYHR basin has approximately 340 lakes $\left(\sim 8235 \mathrm{~km}^{2}\right)$ with areas ranging from $\sim 0.1 \mathrm{~km}^{2}$ to $\sim 2338 \mathrm{~km}^{2}$ (Ma et al., 2010). In particular, some of the large lakes are the main water supply sources of cities nearby; these lakes include the third largest freshwater lake in China, Lake Taihu (supplying the cities of Wuxi, Shanghai, and Suzhou), the fourth largest freshwater lake in China, Lake Hongze (supplying the cities of Huai'an and Suqian, and the eastern branch of China's South-North Water Transfer Project), and the fifth largest freshwater lake in China, Lake Chaohu (supplying the city of Chaohu). However, under the influence of human activities, environmental and ecological degradation problems, such as eutrophication, algal blooms, and the decrease in transparency due to sand dredging activities, are significant in these lakes (Cao et al., 2017; Duan et al., 2017). For example, Lake Chaohu and Lake Taihu are hyper-eutrophic and turbid due to frequent cyanobacterial blooms and resuspended sediments; Lake Hongze is mesotrophic and highly turbid due to large amounts of sediments brought directly into the lake from the Huai River and illegal dredging activities. Monitoring these lakes over the scales over which they vary in space and time necessitates remote sensing algorithms that are able to provide reasonable products across a large range of optical conditions.

The Ocean and Land Colour Instrument (OLCI) on Sentinel-3A is a suitable satellite sensor for monitoring inland lakes with $300 \mathrm{~m} \times 300 \mathrm{~m}$ pixel size, 21 spectral bands $(400-1020 \mathrm{~nm})$ and high signal-to-noise ratio (https://sentinel.esa.int/web/sentinel/technicalguides/sentinel-3-olci). For OLCI, several semi-analytical or neural network (NN) algorithms, i.e., MERIS Case 2 (Doerffer and Schiller, 2007), Case 2 Regional Coast Color (C2RCC) (Brockmann et al., 2016), S3-OLCI Neural Network Swarm (ONNS) (Hieronymi et al., 2017), and Machine Learning Regression Approaches (Ruescas et al., 2018), have been used to estimate IOPs and concentrations of OACs, i.e., Chla, and suspended particulate matter (SPM) in the previous studies. Based on the Case 2 Regional processor (Doerffer and Schiller, 2007), C2RCC was developed for atmospheric correction, and specifically trained for IOPs estimation using a large training data set obtained by radiative transfer simulations (Brockmann et al., 2016). C2RCC is available in ESA's Sentinel toolbox SNAP to generate the IOP products in Case 2 water.

Variations of IOPs in Lake Chaohu, Lake Taihu and Lake Hongze were investigated and monitored based on field-measured data and Sentinel-3A/OLCI images. The primary aims of this study are as follows: 1) analyze the field measured IOPs in three large freshwater lakes in China; 2) develop an IOP inversion algorithm (QAA-based algorithm (QAA-750E)) specifically applicable to optically complex lakes based on Sentinel-3A/OLCI $R_{r s}$ data and validated with in-situ data; and 3) using this algorithm, study the spatial and temporal variations of IOPs, and the OACs (Chla, and SPM) derived from $R_{r s}$ over the three major largest freshwater lakes and other lakes in the LYHR. This study provides a case-study on how to develop and locally optimized inversion algorithm to monitor the distribution of IOPs and OACs in optically complex and highly dynamic lakes (Fig. 1).

\section{Data and methods}

\subsection{Field-measured data}

Lake Taihu, Lake Hongze and Lake Chaohu are the third, fourth, and fifth largest freshwater lakes in China with areas of $\sim 2338$ $\left(33^{\circ} 06^{\prime}-33^{\circ} 40^{\prime} \mathrm{N}, \quad 118^{\circ} 10^{\prime}-118^{\circ} 52^{\prime} \mathrm{E}\right), \quad 1577 \quad\left(33^{\circ} 06^{\prime}-33^{\circ} 40^{\prime} \mathrm{N}\right.$, $\left.118^{\circ} 10^{\prime}-118^{\circ} 52^{\prime} \mathrm{E}\right)$, and $770 \mathrm{~km}^{2}\left(31^{\circ} 25^{\prime}-31^{\circ} 43^{\prime} \mathrm{N}, 117^{\circ} 17^{\prime}-117^{\circ} 51^{\prime} \mathrm{E}\right)$, respectively (Fig. 2) (Tang et al., 2015). Lake Taihu and Lake Chaohu are located in the Lower Reaches of Yangtze River, and Lake Hongze is located in the Lower Reaches of Huai River. The mean water depths are 


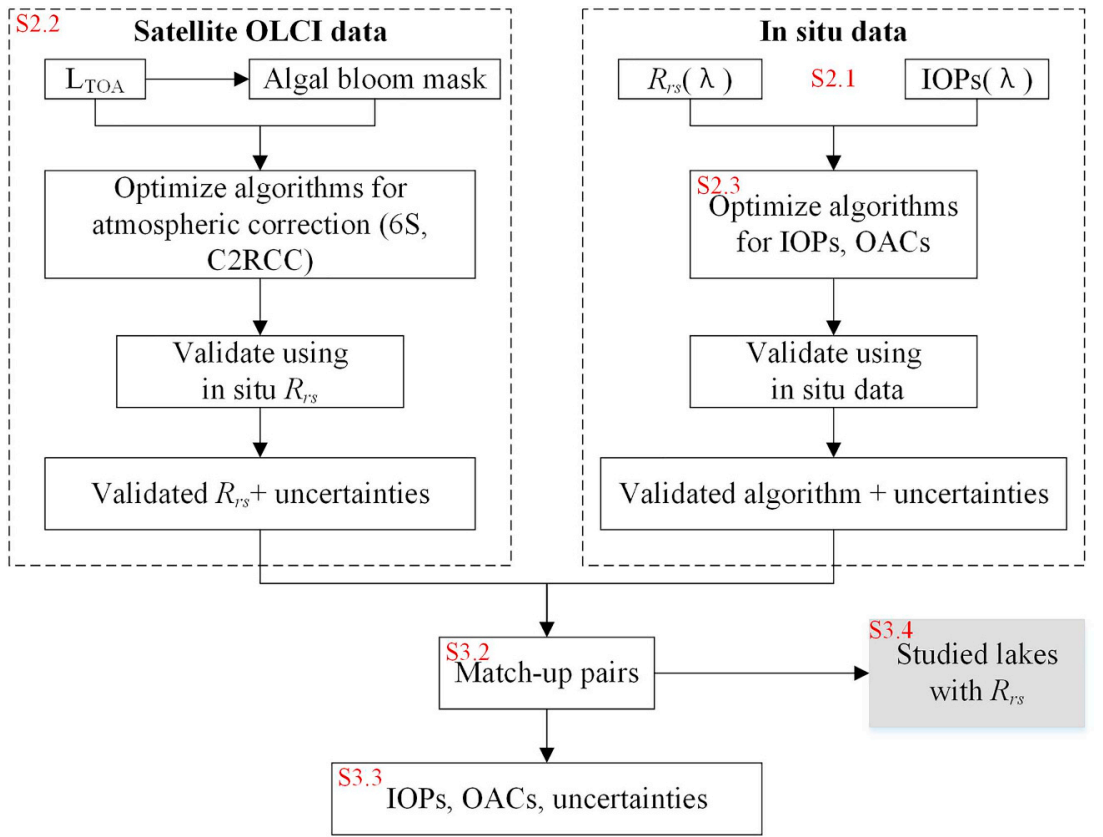

Fig. 1. Framework of the case-study on how to develop and locally optimized inversion algorithm to monitor the distribution of IOPs and OACs. "S" represents "Section", for example, S2.1 represents this part is illustrated in Section 2.1. $\mathrm{L}_{\mathrm{TOA}}$ is the OLCI Level-1B full-resolution data. Algal bloom mask was derived using APA (algae pixel-growing algorithm) algorithm (Zhang et al., 2014) with algal bloom coverage $\geq 10 \%$.
3.0, 1.9, and $1.9 \mathrm{~m}$, and the mean secchi disk depths are $0.27,0.40$, and $0.27 \mathrm{~m}$ in Lake Chaohu, Lake Taihu, and Lake Hongze, respectively. Frequent occurrence of algal blooms and human activities threaten the environment balance, with potential adverse impact on drinking water for people living in the watershed, in Lake Chaohu and Taihu (Qin et al., 2013). Nutrient-rich inflows have led to elevated eutrophication of the western part of Lake Chaohu, where the mean content of total phosphorus (TP) and total nitrogen (TN) were significantly higher than those in the eastern part (Duan et al., 2017; Yang et al., 2013). In addition, Lake Taihu is often turbid due to wind-wave-induced resuspension, whereas the eastern part of Lake Taihu often has aquatic macrophytes. Lake Hongze is a relatively turbid lake with some aquatic macrophytes at its margin (Cao et al., 2017). The three lakes thus represent a wide range of inland lakes with complex optical properties.

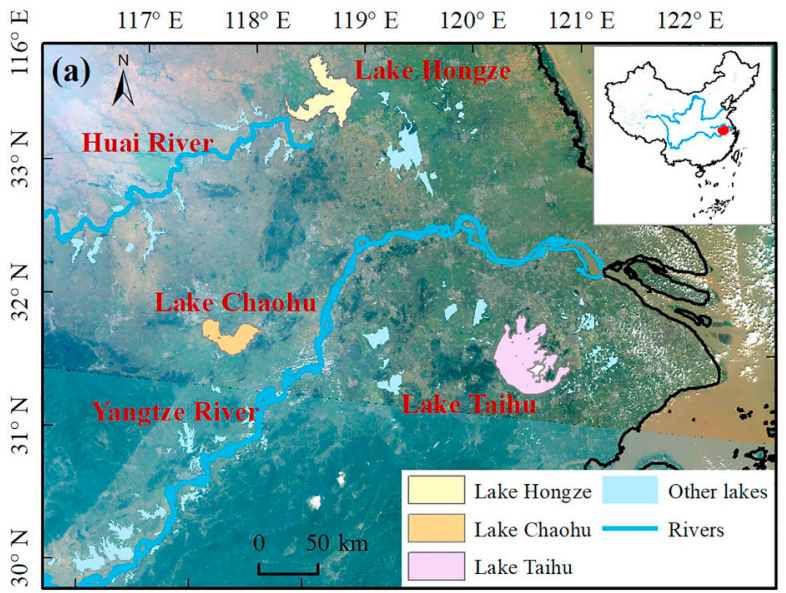

$118^{\circ} 20^{\prime} \mathrm{E} \quad 118^{\circ} 30^{\prime} \mathrm{E} \quad 118^{\circ} 40^{\prime} \mathrm{E} \quad 118^{\circ} 50^{\prime} \mathrm{E} \quad 119^{\circ} 0^{\prime} \mathrm{E}$
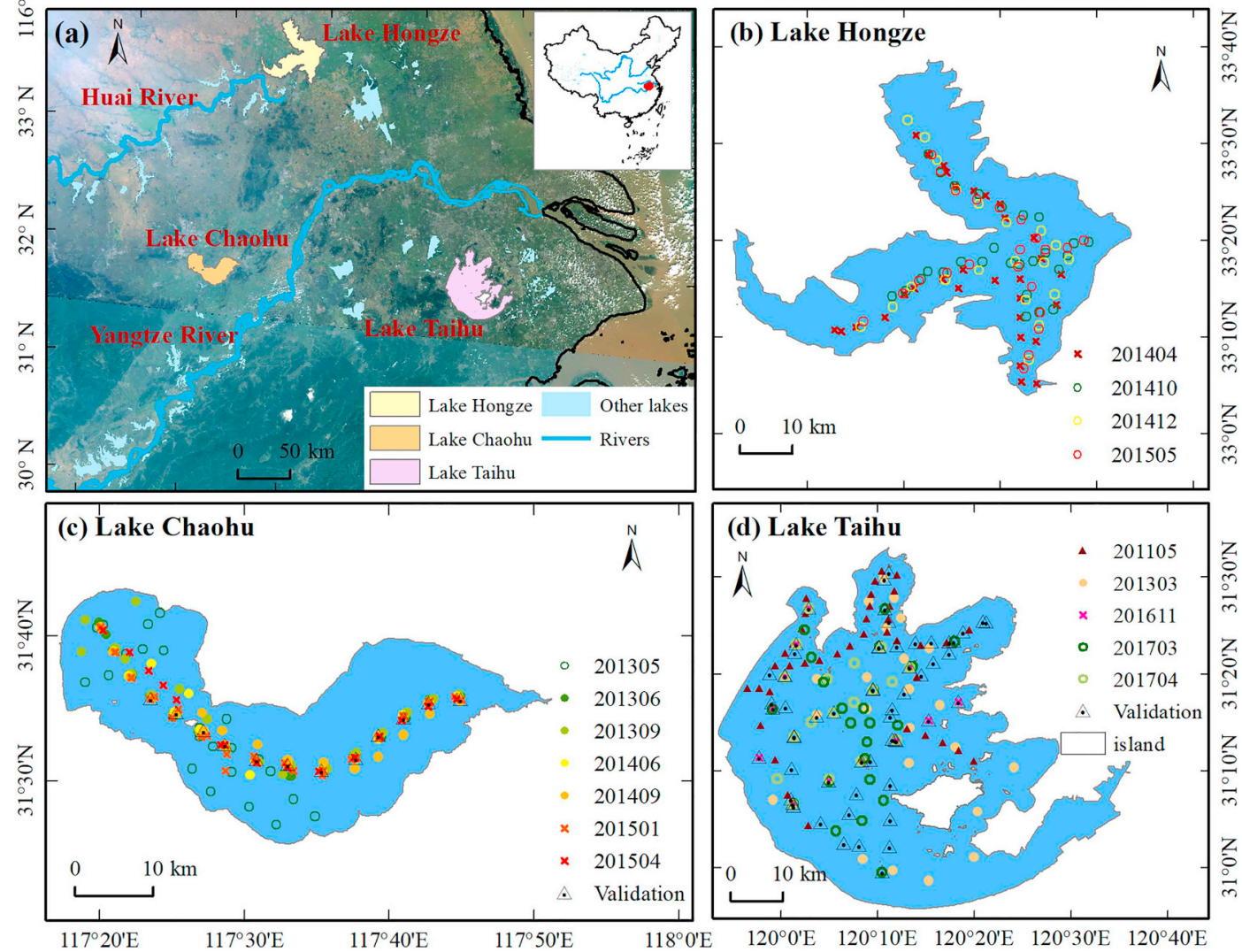

Fig. 2. (a) Location of Lake Chaohu, Lake Taihu, and Lake Hongze in China. They are located in the lower reaches of Yangtze and Huai River (LYHR) basin. Sampling stations of field cruises in (b) Lake Hongze, (c) Lake Chaohu, and (d) Lake Taihu are presented, respectively. 
Field data were collected during eight survey cruises (176 distinct stations) in Lake Chaohu from May 2013 to December 2016, five cruises (129 distinct stations) in Lake Taihu from May 2011 to April 2017, and four cruises (100 distinct stations) in Lake Hongze from April 2014 to May 2015 (Fig. 2). $R_{r s}(\lambda$ ), ranging from $350 \mathrm{~nm}$ to $1050 \mathrm{~nm}$ with an interval of $1 \mathrm{~nm}$, was measured using an ASD field spectrometer (FieldSpec Pro Dual VNIR, Analytical Spectra Devices, Inc.) with viewing direction of $40 \mathrm{deg}$. from the nadir and $135 \mathrm{deg}$. from the Sun (Mobley, 1999). Downwelling plane irradiance $\left(E_{d}(\lambda)\right)$ was derived by measuring radiance of gray panel $\left(L_{p}\right)$.

Spectral absorption coefficients of water constituents include total particulate matter $\left(a_{p}(\lambda)\right)$, phytoplankton $\left(a_{p h}(\lambda)\right)$, NAP (also referred to as the detritus) $\left(a_{d}(\lambda)\right)$, and $\operatorname{CDOM}\left(a_{g}(\lambda)\right)$ were determined using a Shimadzu UV2600 spectrophotometer. Briefly, $a_{p}(\lambda), a_{p h}(\lambda)$, and $a_{d}(\lambda)$ were determined using the quantitative filter technique (QFT) (Mitchell, 1990; Mitchell et al., 2003). Absorbance spectra were corrected for background by subtracting the average absorbance at $750 \mathrm{~nm}$ from the entire spectra and pathlength amplification (Cleveland and Weidemann, 1993; Ylöstalo et al., 2014; Zhang et al., 2007). $a_{d}(\lambda)$ were measured after the pigments were bleached with sodium hypochlorite (Ferrari and Tassan, 1999), and $a_{p h}(\lambda)$ was obtained by subtracting $a_{d}(\lambda)$ from $a_{p}(\lambda)$. Water samples were filtered using $0.22-\mu \mathrm{m}$ pore size filters, and $a_{g}(\lambda)(280 \mathrm{~nm}$ to $700 \mathrm{~nm}$ with $1 \mathrm{~nm}$ interval) was measured using a Shimadzu UV2600 spectrophotometer. The total absorption coefficient spectrum, $a(\lambda)$, is computed from the sum of $a_{p h}(\lambda), a_{d}(\lambda)$, $a_{g}(\lambda)$ and the absorption coefficients of pure water $a_{w}(\lambda)$ (Pope and Fry, 1997):

$a(\lambda)=a_{p h}(\lambda)+a_{d}(\lambda)+a_{g}(\lambda)+a_{w}(\lambda)$

After extraction of pigments using $90 \%$ acetone, the concentration of Chla was measured using a Shimadzu UV2600 spectrophotometer (Gitelson et al., 2008; Werdell et al., 2013). Concentrations of SPM were determined gravimetrically in the laboratory, and suspended particulate inorganic matter (SPIM) was derived gravimetrically by burning organic matter from the filters (Jiang et al., 2012). Suspended particulate organic matter (SPOM) was computed from the difference between SPM and SPIM. Additional information regarding the measurements and processing methods used to derive $R_{r s}(\lambda)$, absorption coefficients, Chla, and SPM can be found in the previous studies (Cao et al., 2017; Xue et al., 2017a; Xue et al., 2017b).

\subsection{Sentinel-3A/OLCI images}

OLCI Level-1B full-resolution data (OL_1_EFR, 300-m) covering the study areas were acquired from the European Space Agency (ESA) Copernicus Open Access Hub (https://scihub.copernicus.eu/dhus/\#/ home). A total of 115 cloud-free OLCI images from November 2016 to December 2017 were retrieved for Lake Chaohu (38 scenes), Lake Taihu (26 scenes), and Lake Hongze (51 scenes). To compute $R_{r}$, an atmospheric correction scheme was applied to each cloud-free Level-1B OLCI scene using the vector version of $6 \mathrm{~S}$ model (Second Simulation of the Satellite Signal in the Solar Spectrum correction scheme) (Vermote et al., 1997), which was proven to be more accurate and efficient in turbid inland waters (Burns and Nolin, 2014). The continental aerosol type and middle latitude atmospheric profiles of the $6 \mathrm{~S}$ model are used in this study. The aerosol optical thickness retrieved by the Aqua/Terra MODIS (Moderate Resolution Imaging Spectroradiometer) surrounding the lakes on the same day were set as input parameters to the $6 \mathrm{~S}$ model (Huang et al., 2015). The mean of the aerosol optical thickness at three pixels at different locations around the lake was used as representative of aerosols present over the whole lake. More details of OLCI image preprocessing can be found in Shen et al. (2017).

$R_{r s}$ derived using $6 \mathrm{~S}$ and C2RCC atmospheric correction algorithms were compared to in situ measured $R_{r s}$ integrated using spectral response functions centered at 443, 560, 665, 674, 709, and $754 \mathrm{~nm}$ (Fig. 3, Table 2). 6S was found to perform better $\left(\mathrm{R}^{2}\right.$ ranging from 0.54 to 0.83 , APD (average absolute percentage difference) ranging from $12.71 \%$ to $50.64 \%$ ) to C2RCC at the selected wavelengths, except 443 and $754 \mathrm{~nm}$ in algal bloom waters $(\mathrm{N}=22)$. Previous studies showed that C2RCC had good performances at 490 to $709 \mathrm{~nm}$, and poor performances in the blue (412 and $443 \mathrm{~nm}$ ) and NIR wavebands (754-865 nm) for the highly absorbing waters in Baltic Sea (Qin et al., 2017). However in our case, C2RCC tended to underestimate $R_{r s}$ with APD $>56 \%$ at the six bands in our dataset. The $6 \mathrm{~S}$ underestimated $R_{r s}$ at $443 \mathrm{~nm}$, and overestimation at $754 \mathrm{~nm}$ with large variations in algal bloom waters (Table 2). Given the superior performance of $6 \mathrm{~S}$, it was applied here to atmospherically correct the OLCI data.

Another source of uncertainties in retrievals comes from floating algal blooms. The floating algae index (FAI) (Hu, 2009) and the algae pixel-growing algorithm (APA) (Zhang et al., 2014), based on Rayleighcorrected reflectance, were used to mask regions of intense algal blooms (algal bloom coverage $\geq 10 \%$ ) (Shen et al., 2017), which were not used in this study. A match-up dataset of Sentinel-3A/OLCI and field-measured data was derived using a time window of $\pm 3 \mathrm{~h}$, and a coefficient of variation $(\mathrm{CV})$ test $(3 \times 3$-pixel centered at the sampling station with CV < 10\%) (Cao et al., 2017; Feng et al., 2012). With these criteria, a total 91 match-up pairs of OLCI-derived $R_{r s}(\lambda)$ and field-measured $R_{r s}(\lambda)$, of which 69 match-up pairs were acquired.

\subsection{QAA-750E algorithm}

An IOP inversion algorithm (denoted as QAA-750E) that is suitable for optically complex lake waters, was developed based on the published QAA (Lee, 2014; Lee et al., 2002), and modified based on the insitu data we collected. QAA-750E contains two parts: Part I, the total absorption coefficients, $a(\lambda)$, and backscattering coefficients, $b_{b}(\lambda)$, were derived from $R_{r s}(\lambda)$ based on a modified QAA scheme by shifting the reference wavelength to $750 \mathrm{~nm}$; and Part II: $a_{d}(\lambda)$ and $a_{p h}(\lambda)$ were estimated using the $b_{b}(\lambda)$ and $a(\lambda)$ derived in Part I, respectively. An empirical formula based on $b_{b}(\lambda)$ was utilized to estimate $a_{d}(443)$, and then a scheme was developed to derive $a_{p h}(443)$ using $a(\lambda)$ at 665 and $674 \mathrm{~nm}$, where the contributions of NAP and CDOM are low in the lakes studied here. $a_{g}(443)$ was derived by subtracting $a_{d}(443)$ and $a_{p h}(443)$ from $a_{n w}(443)$. The general structure of QAA-750E is illustrated in the flowchart (Fig. 4), and the corresponding derivation expressions are listed in Table 3.

\subsubsection{Part I: derivation of total absorption and backscattering coefficients}

Part I of the QAA-750E algorithm is based on the first part of QAAv6 (Lee, 2014), deriving $a(\lambda)$ and $b_{b}(\lambda)$ from $R_{r s}(\lambda)$. Two empirical steps (steps 2 and 4) of QAA-v6, were modified in QAA-750E (highlighted in Table 3 ) in terms of the optical properties of inland waters. As $g_{\text {Lee }}$ $\left(g_{0}=0.084, g_{1}=0.17\right)$ (Lee et al., 1999) was suggested for higher scattering coastal waters (Lee et al., 2002), $\mathrm{g}_{\text {Lee }}$ was used to derive $u(\lambda)$ $\left(=b_{b}(\lambda) /\left(a(\lambda)+b_{b}(\lambda)\right)\right)$ from $r_{r s}(\lambda)$ in the proposed algorithm.

In QAA-v6, $\Delta a\left(\lambda_{0}\right)$, which represents the absorption of dissolved and suspended constituents at $\lambda_{0}(550 \mathrm{~nm}$ or $670 \mathrm{~nm})$, is derived using $r_{r s}(\lambda)$. However, poor performance was obtained by deriving $\Delta a(550)$ or $\Delta a(670)$. Thus, the reference wavelength in calculating $a(\lambda)$ was changed to $750 \mathrm{~nm}$, and $a\left(\lambda_{0}\right)\left(=a_{w}(750)+\Delta a(750)\right)$ was assumed to be $a_{w}(750)\left(\Delta a\left(\lambda_{0}\right)=0\right)$ in step 3 of QAA-750E (Table 3). $b_{b p}(750)$ was then derived in step 4 (Table 3 ).

In step 5 , the power-law exponent value of $b_{b p}(\lambda)(\mathrm{Y})$ was derived from the ratio of $r_{r s}(443)$ to $r_{r s}(560)$ (Lee et al., 2002; Li et al., 2013). The empirical formula of $\mathrm{Y}$ in QAA-v6 was tuned using Ecolight data (Fig. $5 \mathrm{a}, \mathrm{N}=3984$ ), which simulates the underwater light field of our inland lakes using the average SPIM, $a_{g}(440)$, and varying value and vertical profiles of Chla in Xue et al. (2017b). Performance of the simulations was validated using the field measured IOPs and $R_{r s}(\lambda)$ in Lake Chaohu on May 28, 2014 (Xue, 2016). Further, $b_{b p}(\lambda)$ and $a(\lambda)$ were calculated in steps 6-7 using the same semi-analytical equations with QAA-v6. 

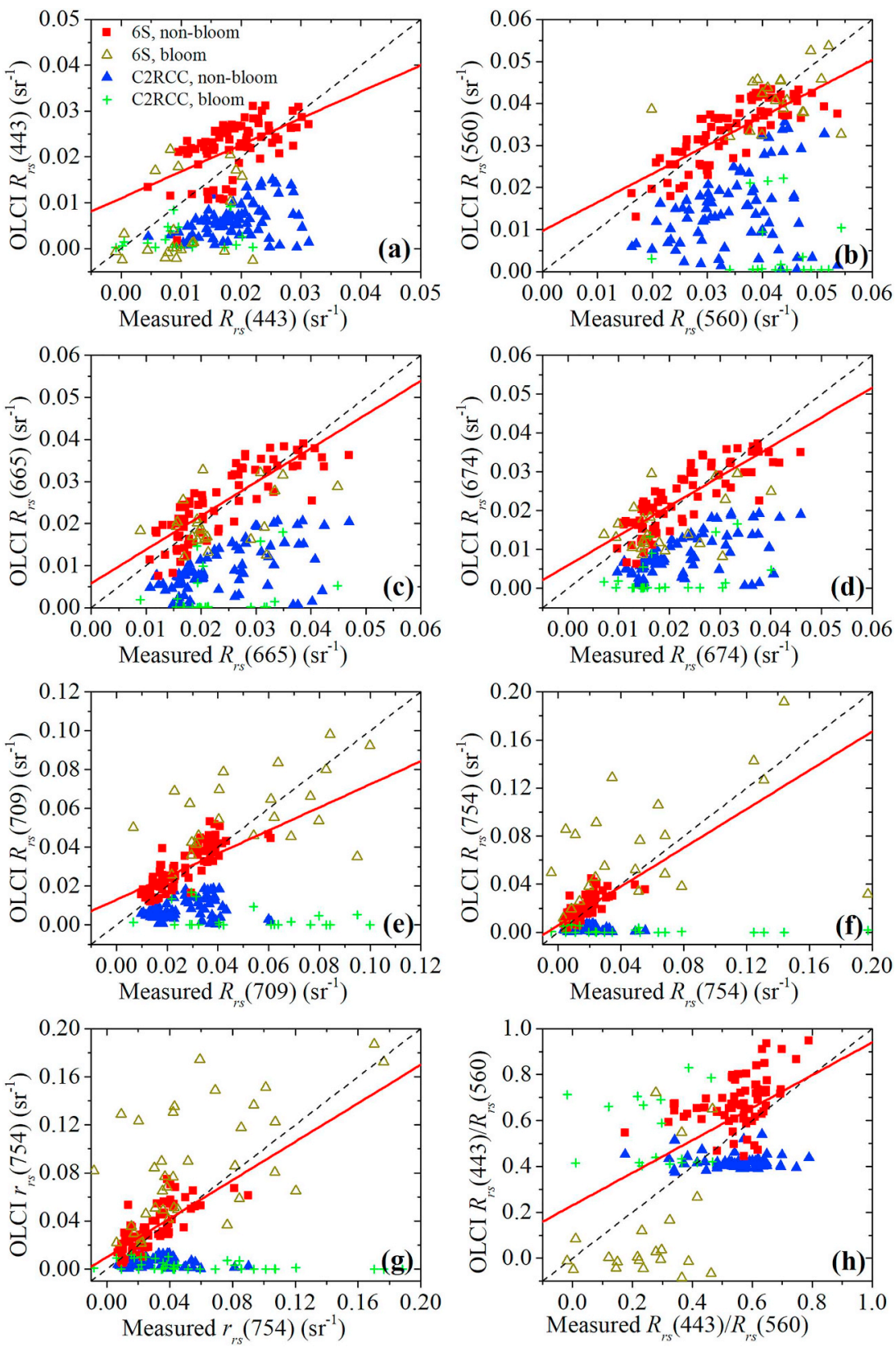

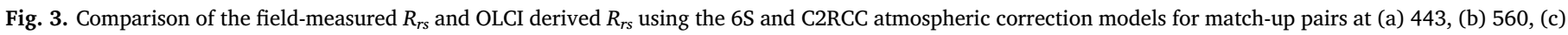

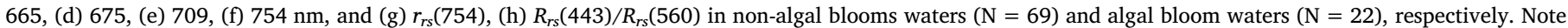
that $r_{r s}(754)$ is the function of $R_{r s}(754)$, showed in Table 3 (Step 1).

\subsubsection{Part II: Derivation of particulate absorption}

NAP is part of the suspended particulates and contributes significantly to the scattering coefficient. Various relationships between $a_{d}(\lambda)$ and $b_{b p}(\lambda)$ have been published and used to estimate $a_{d}(\lambda)$ (Dong et al., 2013; Zhu et al., 2011). In step 8 (Table 3), based on 270 (i.e. $2 / 3$ of the total samples used here to build the model) field measured $a_{d}(443)$ and estimated $b_{b p}(560)$ in Part I, a relationship was established to evaluate $a_{d}(443)\left(\mathrm{R}^{2}=0.64\right.$, RMSE $=0.46 \mathrm{~m}^{-1}$, Fig. $\left.5 \mathrm{~b}\right)$.

Given the high contents of SPIM and CDOM in our lakes, NAP and CDOM have high absorption coefficients value in the blue and green bands. Besides, considering the variability of specific phytoplankton absorption and pigment composition, the $a_{n w}$ at red band (>650 nm) was used to derive $a_{p h}(674)$. In step $9, a_{p h}(674)$ was derived using $a_{n w}(\lambda)$ at 665 and $674 \mathrm{~nm}$ derived from step 7 of Part I (Table 3). $\varepsilon$ was defined as the ratio of $a_{n w}(\lambda)-a_{p h}(\lambda)$ at 674 and $665 \mathrm{~nm}$ : $\varepsilon=\frac{a_{n w}(674)-a_{p h}(674)}{a_{n w}(665)-a_{p h}(665)}$

Then, $a_{p h}(674)$ can be expressed based on Eq. (2):

$a_{p h}(674)=a_{n w}(674)-\varepsilon\left(a_{n w}(665)-a_{p h}(665)\right)$

A good relationship was found between $a_{p h}(674)$ and $a_{p h}(665)$ $\left(\mathrm{R}^{2}=0.97, \mathrm{RMSE}=0.17 \mathrm{~m}^{-1}\right.$, Fig. $\left.5 \mathrm{c}\right)$ :

$a_{p h}(665)=\mathrm{S}_{1} \times a_{p h}(674)$

Where, $\mathrm{S}_{1}=0.839$. Combining Eqs. (3)-(4), $a_{p h}(674)$ can be calculated as follows:

$a_{p h}(674)=a_{n w}(674)-\varepsilon \times a_{n w}(665)+\varepsilon \times\left(\mathrm{S}_{1} \times a_{p h}(674)\right)$

$a_{p h}(674)=\frac{a_{n w}(674)-\varepsilon \times a_{n w}(665)}{\left(1-\varepsilon \times S_{1}\right)}$ 
Table 2

Performance of atmospheric correction using $6 \mathrm{~S}$ and C2RCC on $R_{r s}(443,560,665,674,709,754), r_{r s}(754)$, and $R_{r s}(443) / R_{r s}(560)$ in non-bloom waters $(\mathrm{N}=69)$ and bloom waters $(\mathrm{N}=22)$. The corresponding scattering plots are showed in Fig. 3.

\begin{tabular}{|c|c|c|c|c|c|c|c|c|c|}
\hline & \multirow[t]{2}{*}{ Band } & \multicolumn{4}{|l|}{$6 S$} & \multicolumn{4}{|l|}{ C2RCC } \\
\hline & & $\mathrm{R}^{2}$ & RMSE & APD & Bias & $\mathrm{R}^{2}$ & RMSE & APD & Bias \\
\hline \multirow[t]{9}{*}{ Non- bloom } & $R_{r s}(443)$ & 0.63 & 0.006 & 34.07 & 0.004 & 0.36 & 0.014 & 67.22 & -0.013 \\
\hline & $R_{r s}(560)$ & 0.79 & 0.005 & 12.71 & -0.001 & 0.25 & 0.022 & 56.27 & -0.020 \\
\hline & $R_{r s}(665)$ & 0.85 & 0.005 & 19.89 & 0.001 & 0.52 & 0.016 & 60.86 & -0.015 \\
\hline & $R_{r s}(674)$ & 0.83 & 0.005 & 21.11 & 0.001 & 0.56 & 0.016 & 61.87 & -0.014 \\
\hline & $R_{r s}(709)$ & 0.83 & 0.010 & 25.76 & 0.002 & 0.13 & 0.023 & 66.61 & -0.019 \\
\hline & $R_{r s}(754)$ & 0.80 & 0.021 & 50.34 & 0.001 & 0.03 & 0.028 & 74.42 & -0.015 \\
\hline & $r_{r s}(754)$ & 0.80 & 0.025 & 47.41 & 0.002 & 0.03 & 0.038 & 73.79 & -0.024 \\
\hline & $R_{r s}(443)$ & 0.46 & 0.171 & 30.53 & 0.128 & 0.03 & 0.176 & 28.88 & -0.137 \\
\hline & $/ R_{r s}(560)$ & & & & & & & & \\
\hline \multirow[t]{9}{*}{ Bloom } & $R_{r s}(443)$ & 0.15 & 0.010 & 157.06 & -0.006 & 0.12 & 0.010 & 68.88 & -0.006 \\
\hline & $R_{r s}(560)$ & 0.79 & 0.009 & 17.25 & -0.004 & -0.50 & 0.040 & 86.63 & -0.037 \\
\hline & $R_{r s}(665)$ & 0.33 & 0.008 & 72.88 & -0.003 & -0.07 & 0.019 & 81.89 & -0.017 \\
\hline & $R_{r s}(674)$ & 0.20 & 0.009 & 19.31 & -0.003 & 0.12 & 0.016 & 74.53 & -0.014 \\
\hline & $R_{r s}(709)$ & 0.74 & 0.021 & 69.10 & 0.012 & -0.61 & 0.048 & 87.25 & -0.039 \\
\hline & $R_{r s}(754)$ & 0.70 & 0.041 & 143.88 & 0.027 & -0.67 & 0.058 & 78.28 & -0.038 \\
\hline & $r_{r s}(754)$ & 0.70 & 0.056 & 115.87 & 0.038 & -0.67 & 0.083 & 78.10 & -0.056 \\
\hline & $R_{r s}(443)$ & 0.21 & 0.270 & 180.80 & -0.117 & -0.14 & 2.523 & 3369 & 1.172 \\
\hline & $/ R_{r s}(560)$ & & & & & & & & \\
\hline
\end{tabular}

In addition, $\varepsilon$ can also be written as $a_{d g}(674) / a_{d g}(665)$, which is the function of spectral slope of $a_{d g}(\lambda)$ spectrum $\left(S_{d g}\right)$. As variation of $S_{d g}$ is relatively low in our data sets, the average $S_{d g}\left(0.014 \pm 0.002 \mathrm{~nm}^{-1}\right)$ was used to compute $\varepsilon$.

$\varepsilon=\frac{a_{d g}(674)}{a_{d g}(665)}=\frac{\exp \left[S_{d g} \times(443-674)\right]}{\exp \left[S_{d g} \times(443-665)\right]}=\exp \left[-9 \times S_{d g}\right]=0.882$

$a_{p h}(443)$ was then derived by $\left(\mathrm{R}^{2}=0.89\right.$, RMSE $=0.28 \mathrm{~m}^{-1}$, Fig. $\left.5 \mathrm{~d}\right)$ :

$a_{p h}(443)=1.75 a_{p h}(674)^{0.906}$

$a_{g}(443)$ is then derived by subtracting $a_{d}(443)$ and $a_{p h}(443)$ from $a_{n w}(443)$. Note that this subtraction propagates errors produced in the former steps into $a_{g}(443)$.

Then, OLCI-derived $R_{r s}(\lambda)$ data were used to derive IOPs using the above IOP inversion algorithm. Pixels identified as clouds (quality flags in OLCI L1B data), and algal blooms (APA, algal bloom coverage $\geq 10 \%$ ) were masked and not used. Daily mean and seasonal mean IOPs of each lake were generated from the 115 OLCI images over the lakes.

\subsection{Error propagation analysis and accuracy assessment}

Algebraic error propagation analysis can provide an effective way to assess model sensitivity and quantify uncertainties of IOPs (Werdell et al., 2018). For instance, the uncertainties propagate to QAA-derived IOPs from parameterization and assumption in the early stage of the algorithm were estimated (Lee et al., 2010b). Uncertainties associated with IOPs derived by QAA-750E were calculated on a pixel-by-pixel basis to analyze the error propagation following the steps in the proposed algorithm. The sequence of computational steps (Eqs. (A1)-(A12)) involved in the error propagation analysis of the proposed

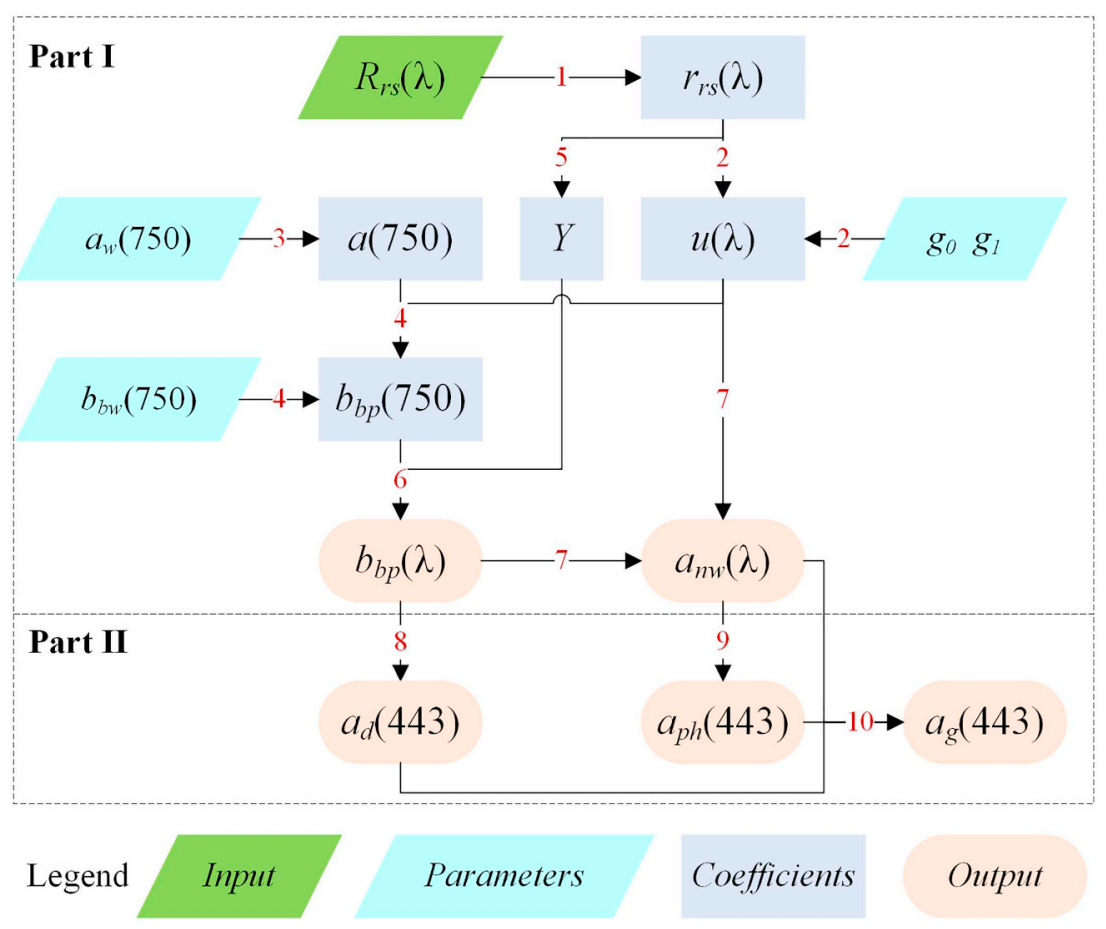

Fig. 4. Flow chart of QAA-750E algorithm. Input parameters are remote sensing reflectance $\left(R_{r s}(\lambda), s^{-1}\right) . r_{r s}(\lambda)$ is the remote sensing reflectance just below water surface, derived in step 1 of Table 3. $u(\lambda)=b_{b}(\lambda) /\left(b_{b}(\lambda)+a(\lambda)\right)$. Output variables are backscattering particulate coefficient $\left(b_{b p}(\lambda), \mathrm{m}^{-1}\right)$, total non-water absorption coefficient $\left(a_{n w}(\lambda), \mathrm{m}^{-1}\right)$, absorption coefficient of NAP and phytoplankton at $443 \mathrm{~nm}$ ( $\left.a_{d}(443), a_{p h}(443), \mathrm{m}^{-1}\right) . b_{b p}(\lambda)$ and $a_{n w}(\lambda)$ were first derived in Part I of QAA-750E; $a_{d}(443)$ and $a_{p h}(443)$ were then determined using $b_{b p}(\lambda)$ and $a_{n w}(\lambda)$, respectively. The equations used in each step are presented in Table 3. 
Table 3

Steps of QAA-750E algorithm. Steps with grey background were different from those of QAA.

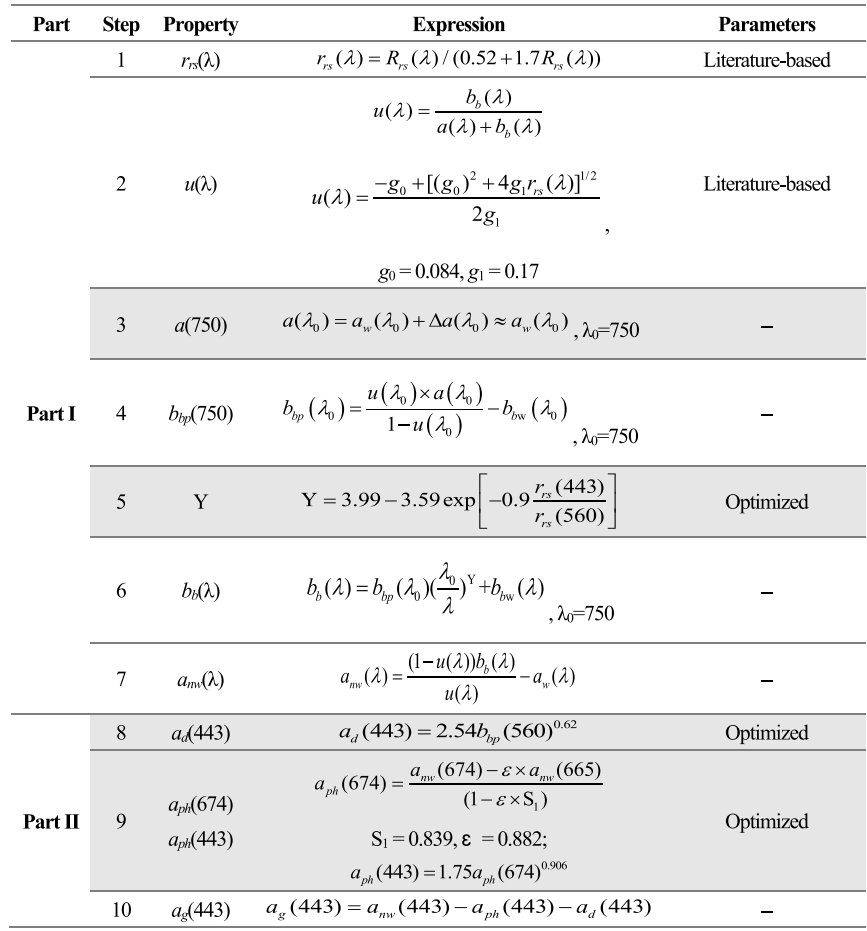
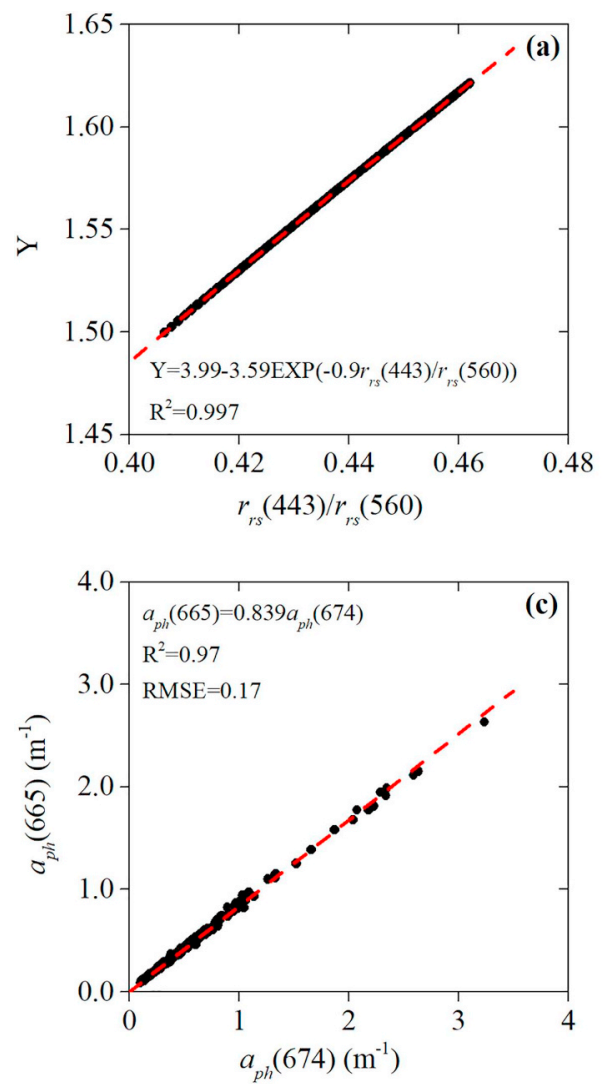

algorithm are presented in Appendix A. The total uncertainties (including measurement uncertainties, uncertainties due to spatial variability within a pixel, and model uncertainties) can be evaluated from the match-up statistics.

To evaluate the performance of the algorithm, the APD (\%), RMSE, unbiased RMSE in relative percentage (URMSE, \%), and bias were calculated to describe the difference between the field data $\left(\mathrm{X}_{\mathrm{i}}\right)$ and the modelled data $\left(\mathrm{Y}_{\mathrm{i}}\right) \cdot 2 / 3$ of the field data $(\mathrm{N}=270)$ were used to build the algorithm, and the remaining $1 / 3$ of the field data and 38 match-up pairs of IOPs were used to validate the algorithm. These parameters are defined as follows:

$\mathrm{APD}=\frac{1}{\mathrm{n}} \sum_{i=1}^{n} \frac{\left|Y_{i}-X_{i}\right|}{X_{i}} \times 100 \%$

$\operatorname{RMSE}=\sqrt{\frac{1}{\mathrm{n}} \sum_{i=1}^{n}\left(\log 10\left(Y_{i}\right)-\log 10\left(X_{i}\right)\right)^{2}}$

URMSE $=\sqrt{\frac{1}{\mathrm{n}} \sum_{i=1}^{n}\left(\frac{Y_{i}-X_{i}}{0.5\left(Y_{i}+X_{i}\right)}\right)^{2}} \times 100 \%$

bias $=\frac{1}{\mathrm{n}} \sum_{i=1}^{n}\left[\log 10\left(Y_{i}\right)-\log 10\left(X_{i}\right)\right]$

Data were log-transformed prior to statistical analysis because IOP data cover a large dynamic range. URMSE was used to avoid deviations that cause skewed error distributions (Qi et al., 2014; Stanford et al., 2002).
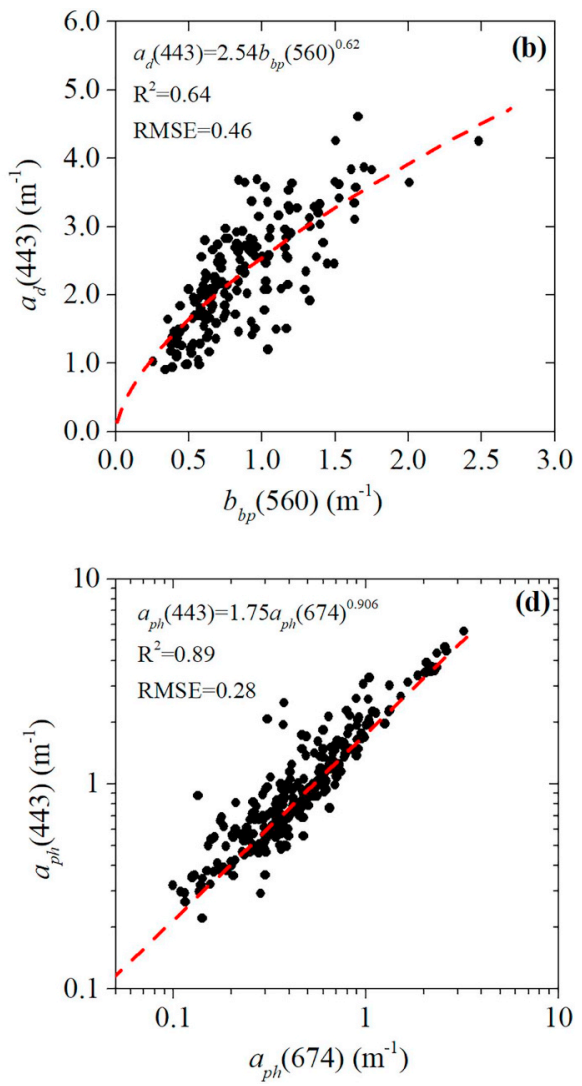

Fig. 5. (a) Determination of Y based on Ecolight simulated $r_{r s}$ in Xue et al. (2017b). Relationships between (b) $a_{d}(443)$ and $b_{b p}(560)$, (c) $a_{p h}(665)$ and $a_{p h}(674)$, (d) $a_{p h}(443)$ and $a_{p h}(674)$ used in QAA-750E. 
Table 4

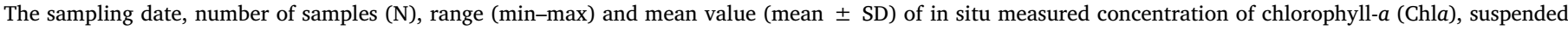

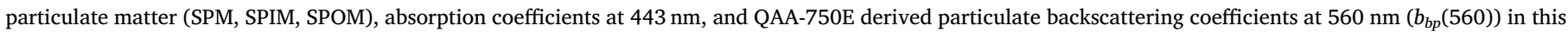
study. Note that abbreviations and symbols can be seen in Table 1, and the details of sampling stations and time can be seen from Fig. 2.

\begin{tabular}{|c|c|c|c|c|c|c|}
\hline Lake & \multicolumn{2}{|c|}{ Lake Chaohu (CH) } & \multicolumn{2}{|c|}{ Lake Taihu (TH) } & \multicolumn{2}{|c|}{ Lake Hongze (HZH) } \\
\hline Time & \multicolumn{2}{|c|}{ May 2013-December 2016} & \multicolumn{2}{|c|}{ May 2011-April 2017} & \multicolumn{2}{|c|}{ April 2014-May 2015} \\
\hline \multirow[t]{2}{*}{$\mathrm{N}$} & \multicolumn{2}{|l|}{176} & \multicolumn{2}{|l|}{129} & \multicolumn{2}{|l|}{100} \\
\hline & \multicolumn{2}{|l|}{ Range mean } & \multicolumn{2}{|l|}{ Range mean } & \multicolumn{2}{|l|}{ Range mean } \\
\hline Chla $\left(\mathrm{mg} / \mathrm{m}^{3}\right)$ & $6.85-138.55$ & $38.37 \pm 28.94$ & $2.47-225.56$ & $34.68 \pm 36.21$ & $2.70-85.64$ & $11.85 \pm 10.00$ \\
\hline SPM (mg/L) & $12.00-133.00^{\mathrm{b}}$ & $45.52 \pm 20.81$ & $5.00-180.00$ & $60.85 \pm 38.73$ & $13.33-110.00$ & $44.83 \pm 18.44$ \\
\hline SPIM (mg/L) & $2.00-105.00^{\mathrm{b}}$ & $30.38 \pm 19.88$ & $0.50-157.33$ & $43.61 \pm 35.64$ & $4.67-80.00$ & $31.65 \pm 15.60$ \\
\hline SPOM (mg/L) & $1.00-40.00^{\mathrm{b}}$ & $15.14 \pm 8.31$ & $1.00-64.00$ & $17.24 \pm 13.03$ & $1.00-50.00$ & $13.18 \pm 7.67$ \\
\hline$a(443)\left(\mathrm{m}^{-1}\right)$ & $1.93-9.14$ & $4.38 \pm 1.30$ & $1.12-11.48$ & $4.84 \pm 2.17$ & $2.04-7.55$ & $4.08 \pm 1.12$ \\
\hline$a_{d}(443)\left(\mathrm{m}^{-1}\right)$ & $0.76-6.98$ & $2.34 \pm 0.90$ & $0.17-7.60$ & $2.36 \pm 1.59$ & $0.49-5.94$ & $2.42 \pm 1.01$ \\
\hline$a_{p h}(443)\left(\mathrm{m}^{-1}\right)$ & $0.30-5.50$ & $1.23 \pm 0.92$ & $0.08-7.65$ & $1.50 \pm 1.28$ & $0.22-2.04$ & $0.70 \pm 0.39$ \\
\hline$a_{g}(443)\left(\mathrm{m}^{-1}\right)$ & $0.16-4.26$ & $0.81 \pm 0.49$ & $0.32-4.08$ & $0.97 \pm 0.65$ & $0.27-2.41$ & $0.96 \pm 0.33$ \\
\hline$b_{b p}(560)\left(\mathrm{m}^{-1}\right)^{\mathrm{a}}$ & $0.27-2.29$ & $0.88 \pm 0.35$ & $0.11-3.48^{\mathrm{c}}$ & $1.10 \pm 0.65$ & $0.08-3.21$ & $1.03 \pm 0.53$ \\
\hline
\end{tabular}

a Represents $b_{b p}(560)$ values were derived with QAA-750E.

b Represents $\mathrm{N}=154$.

c Represents $\mathrm{N}=93$.

(a)

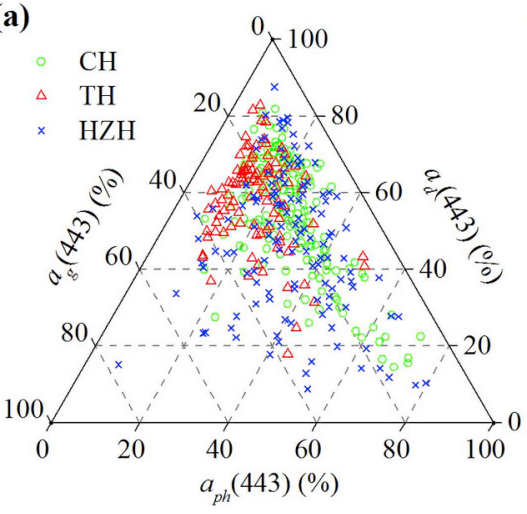

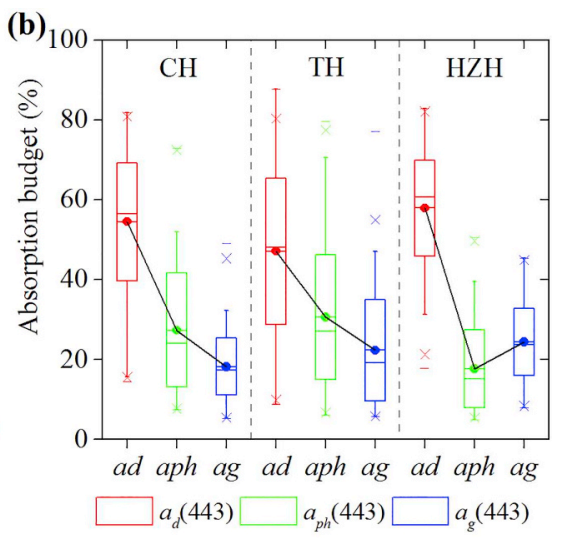
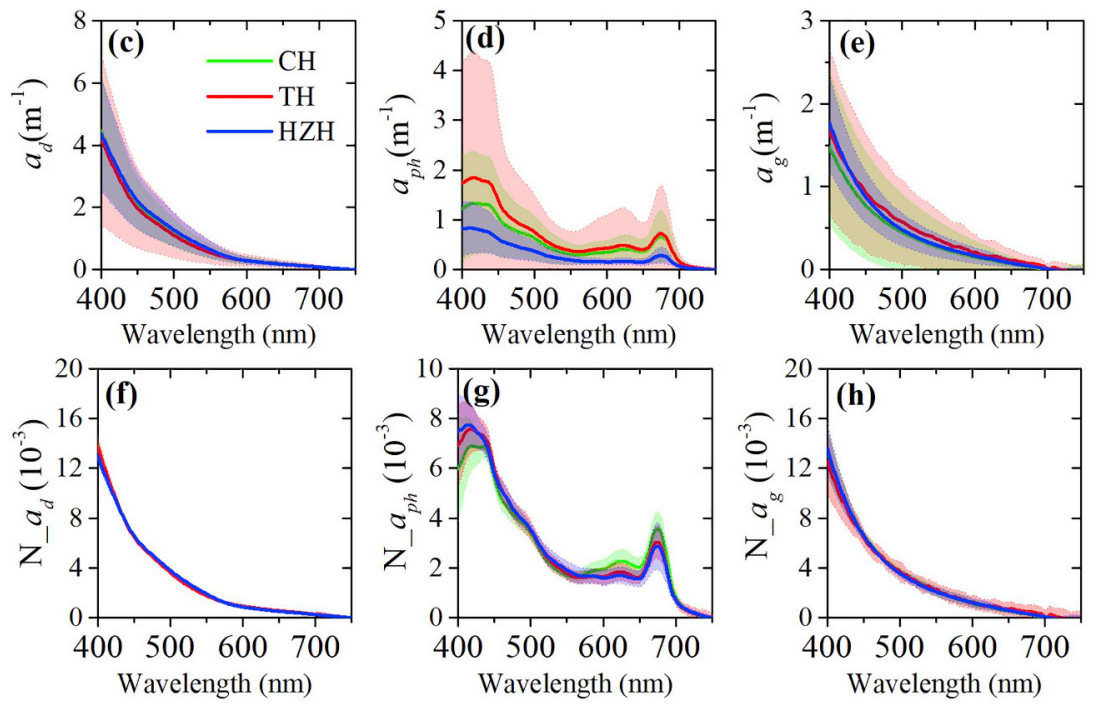

Fig. 6. (a) Contribution of $a_{d}(443), a_{p h}(443)$, and $a_{g}(443)$ to total non-water absorption at $443 \mathrm{~nm}\left(a_{n w}(443)\right)$ in $\mathrm{CH}, \mathrm{TH}$, and HZH dataset. (b) Statistics of absorption budget of each lake, "ad" represents absorption budget of $a_{d}(443)$, " $a p h$ " represents absorption budget of $a_{p h}(443)$, "ag" represents absorption budget of $a_{g}$ (443). The black lines exhibit the average contribution of each component to $a_{n w}(443)$ in each lake. (c-e) Statistics value (mean \pm SD) of absorption coefficients spectra of (c) NAP, (d) phytoplankton, and (e) CDOM in $\mathrm{CH}$, $\mathrm{TH}$, and $\mathrm{HZH}$ dataset, respectively. (f-h) Statistics value (mean $\pm \mathrm{SD}$ ) of normalized absorption coefficients spectra of (f) NAP, (g) phytoplankton, and (h) CDOM in $\mathrm{CH}, \mathrm{TH}$, and $\mathrm{HZH}$ dataset, respectively.

\section{Results}

\subsection{Bio-optical properties of optically complex lakes}

Large range and significant variability of OACs and absorption coefficients were observed in Lake Chaohu ( $\mathrm{CH}$ dataset, $\mathrm{N}=176$ ), Lake Taihu (TH dataset, $\mathrm{N}=129$ ), and Lake Hongze (HZH dataset, $\mathrm{N}=100$ )
(Table 4, Fig. 6). $\mathrm{CH}$ and $\mathrm{TH}$ had similar Chla averages $\left(38.37 \pm 28.94 \mathrm{mg} / \mathrm{m}^{3}\right.$ in $\mathrm{CH}$ and $34.68 \pm 36.21 \mathrm{mg} / \mathrm{m}^{3}$ in $\left.\mathrm{TH}\right)$ and SPM $(45.52 \pm 20.81 \mathrm{mg} / \mathrm{L}$ in $\mathrm{CH}$ and $60.85 \pm 38.73 \mathrm{mg} / \mathrm{L}$ in $\mathrm{TH})$. However, TH had wider ranges of Chla $\left(2.47-225.56 \mathrm{mg} / \mathrm{m}^{3}\right)$ and SPM $(5.00-180.00 \mathrm{mg} / \mathrm{L})$ than $\mathrm{CH}$ (Chla $6.85-138.55 \mathrm{mg} / \mathrm{m}^{3}$ and $\mathrm{SPM}$ $12.00-133.00 \mathrm{mg} / \mathrm{L}$ ). In particular, the inorganic matter (SPIM) of TH $(0.50-157.33,43.61 \pm 35.64 \mathrm{mg} / \mathrm{L})$ was approximately 1.5 times that 
of $\mathrm{CH}(2.00-105.00,30.38 \pm 19.88 \mathrm{mg} / \mathrm{L})$. In other words, $\mathrm{CH}$ has more organic matter (SPOM:SPM $=33.24 \%$ ) with higher Chla $\left(38.37 \pm 28.94 \mathrm{mg} / \mathrm{m}^{3}\right)$ than TH (SPOM:SPM $=28.33 \%$; Chla: $34.68 \pm 36.21 \mathrm{mg} / \mathrm{m}^{3}$ ). Unlike Lake Chaohu and Lake Taihu, which are eutrophic, Lake Hongze is mesotrophic with lower magnitude and range of Chla $\left(2.70-85.64,11.85 \pm 10.00 \mathrm{mg} / \mathrm{m}^{3}\right)$ and $\mathrm{SPM}$ $(13.33-110.00,44.83 \pm 18.44 \mathrm{mg} / \mathrm{L})$ but with higher portion of inorganic matter (SPIM:SPM $=70.60 \%$ ). The differences in the content and proportion of OACs in these lakes leads to significant differences in the optical properties of the water bodies.

IOPs, including absorption coefficients such as $a(443), a_{d}(443)$, $a_{p h}(443)$, and $a_{g}(443)$, as well as backscattering coefficient, e.g. $b_{b p}(560)$, reflect the variations and characteristics of OACs in the three lakes. On average, $55 \%$ of $a_{n w}$ (443) was attributed by NAP in the three lakes, while $26 \%$ and $19 \%$ was attributed by the phytoplankton and CDOM at $443 \mathrm{~nm}$, respectively (Fig. 6a-6b). Lake Chaohu and Lake Taihu had similar optical properties. For instance, the average $a(443)$ of $\mathrm{CH}$ and $\mathrm{TH}$ datasets were $4.38 \pm 1.30 \mathrm{~m}^{-1}\left(1.93-9.14 \mathrm{~m}^{-1}\right)$ and $4.84 \pm 2.17 \mathrm{~m}^{-1}\left(1.12-11.48 \mathrm{~m}^{-1}\right)$, respectively. Comparably, Lake Taihu had a slightly higher range and variability of $a_{d}(443)(0.17-7.60$, $\left.2.36 \pm 1.59 \mathrm{~m}^{-1}\right)$ and $b_{b p}(560)\left(1.10 \pm 0.65,0.11-3.48 \mathrm{~m}^{-1}\right)$ than those of Lake Chaohu ( $a_{d}(443), 0.76-6.98,2.34 \pm 0.90 \mathrm{~m}^{-1} ; b_{b p}(560)$, $0.88 \pm 0.35,0.27-2.29 \mathrm{~m}^{-1}$ ). Lake Chaohu and Lake Taihu had large variations of phytoplankton, while Lake Hongze had lower variability of $a_{p h}(\lambda)$. For instance, average $a_{p h}(443)$ of HZH dataset $(0.22-2.04$, $0.70 \pm 0.39 \mathrm{~m}^{-1}$ ) was approximately less than half of the average $a_{p h}(443)$ in $\mathrm{CH}\left(0.30-5.50,1.23 \pm 0.92 \mathrm{~m}^{-1}\right)$ and TH $(0.08-7.65$, $1.50 \pm 1.28 \mathrm{~m}^{-1}$ ) datasets. Lake Hongze had similar average $a_{g}(\lambda)$ with those of Lake Chaohu and Lake Taihu, but obvious low variability. Overall, the three large lakes in the LYHR basin exhibited OACs and IOPs with wide ranges and varying characteristics.

\subsection{Performance of QAA-75OE on field data and OLCI data}

\subsubsection{Validation of the algorithm using field data}

Using the remaining $1 / 3$ of the field data as the validation dataset, the field-measured $R_{r s}(\lambda)$ values of the $\mathrm{CH}$, TH and $\mathrm{HZH}$ datasets were fed into QAA-750E to assess the algorithm performance at four bands: 443, 560, 665, and $674 \mathrm{~nm}$ (data not shown). QAA-750E had similar performance in the four wavelengths, and performed well in retrieving $a(\lambda)$ with average APD of $19.3 \%$, RMSE $<0.2 \mathrm{~m}^{-1}$, bias $<0.15 \mathrm{~m}^{-1}$, and $\mathrm{R}^{2}>0.67$. Field-measured $a_{d}(443)$ and $a_{p h}(443)$ were then used to validate Part II of QAA-750E. The mean APD of $a_{d}(443)$ was $22.1 \%$ with RMSE of $0.11 \mathrm{~m}^{-1}\left(\mathrm{R}^{2}=0.72\right)$; the mean APD in deriving $a_{p h}(443)$ was $35.2 \%$, and RMSE value was $0.19 \mathrm{~m}^{-1}\left(\mathrm{R}^{2}=0.68\right)$; and the mean APD in deriving $a_{g}(443)$ was $71.2 \%$, and RMSE value was $0.48 \mathrm{~m}^{-1}$ $\left(\mathrm{R}^{2}=0.26\right)$. For most water quality applications, such statistics are considered good and the derived $a(\lambda), a_{d}(443)$, and $a_{p h}(443)$ are of utility to study water quality.

The proposed model was then applied to the Sentinel-3A/OLCI data, and validated using the field measured and OLCI-derived match-up pairs of absorption coefficients $(\mathrm{N}=38)$ to assess the feasibility of the algorithm in OLCI data (Fig. 7). The error bars indicated the uncertainties associated to IOPs computed using error propagation in the proposed algorithm. $a(443)$ had better performance (RMSE $=0.18 \mathrm{~m}^{-1}$, URMSE $=29.1 \%$ ) than that of 560, 665, and $675 \mathrm{~nm}$ (RMSE $\geq 0.23 \mathrm{~m}^{-1}$, URMSE $\geq 49.8 \%$ ). Compared to IOP products inverted using C2RCC for atmospheric correction, the accuracy of the absorption coefficients at $443 \mathrm{~nm}\left(a(443), a_{d}(443), a_{p h}(443)\right.$, and $a_{g}(443)$ ) improved (Fig. 7a, e, f, h). The large uncertainties in $a_{g}(443)$ indicated the limitation of our model regarding this parameter.

\subsubsection{Uncertainties associated with IOPS}

As an example of an OLCI derived result, Fig. 8 shows the RGB images, QAA-750E-derived $a_{d}(443), a_{p h}(443), a_{g}(443)$, and their relative uncertainty values (RU, ratio of uncertainty value to the corresponding absorption coefficient) in the different lakes. Spatially, $a_{d}(443)$ and $a_{p h}(443)$ had large RU in the area with low derived $a_{d}(443)$ and $a_{p h}(443)$ (Fig. 8b-8e). Particularly, when $a_{d}(443)<1.0 \mathrm{~m}^{-1}$ or $a_{p h}(443)<0.5 \mathrm{~m}^{-1}$, the RU of $a_{d}(443)$ and $a_{p h}(443)$ can reach $\sim 23 \%$. RU of $a_{g}(443)$ was considerably higher, especially in areas with high $a_{d}(443)$ (Fig. 8b, f), indicating the difficulty of obtain accurate $a_{g}(443)$ using our scheme in waters with high NAP absorption.

\subsection{Spatial and temporal variations of IOPs derived from OLCI data}

The proposed QAA-750E algorithm was applied to the atmospherically corrected $R_{r s}(\lambda)$ of OLCI images to map IOPs of the three lakes in 2017. Seasonally averaged OLCI-derived IOPs (a(443), $b_{b p}(560), a_{d}(443)$, and $\left.a_{p h}(443)\right)$ showed significant spatial and temporal variability in spring (March to May), summer (June to August), autumn (September to November), and winter (December to February) (Fig. 9). Generally, a(443) varied largely in Lake Chaohu and Lake Taihu, but demonstrated lower variability in Lake Hongze (Fig. 9a). High $a$ (443) was observed in the western and eastern part of Lake Chaohu in summer and autumn, as well as in the open areas and southwest part of Lake Taihu in spring and winter (Fig. 9a). $b_{b p}(560)$ and $a_{d}(443)$ were relatively lower in the western part of Lake Chaohu in spring and winter, but obviously high in the open areas and southwest part of Lake Taihu in spring and winter, which indicated the NAP domination at $443 \mathrm{~nm}$ in this region and time period in Lake Taihu (Fig. 9b-c). Lake Hongze had slightly high $b_{b p}(560)$ and $a_{d}(443)$ in the central and southern part of the lake from summer to winter, which indicated the large amount of sediment brought directly into the lake from the Huai River (Fig. 9b-c). The western part of Lake Chaohu and several bays of Lake Taihu exhibited high $a_{p h}(443)$ in summer and autumn, whereas obviously lower $a_{p h}(443)$ was observed in the open areas and southwest part of Lake Taihu in spring and winter (Fig. 9d). Lake Hongze had relatively small spatial variations of IOPs and low magnitude of $a_{p h}(443)$ with considerably lower $a_{p h}(443)$ in the southern part than that in the northern part of the lake (Fig. 9d).

Daily averaged IOPs derived using OLCI data were calculated to observe the temporal variability of IOPs in 2017 in Lake Chaohu, Lake Taihu and Lake Hongze (Fig. 10). a(443) did not show regular temporal trend, and had relatively high values from May to September (Fig. 10a-c). No could-free scenes were available from July to September in Lake Taihu. $b_{b p}(560)$ and $a_{d}(443)$ exhibited similar temporal distribution and had high variations in Lake Chaohu from July to August, and in Lake Hongze from July to September (Fig. 10d-i). $a_{d}(443)$ had no significant seasonal variability and had relatively high daily mean value and large variations in the three lakes. However, $a_{p h}(443)$ was significantly lower than $a_{d}(443)$, and showed different seasonal variations in the three lakes. $a_{p h}(443)$ showed large variability in Lake Chaohu and Lake Taihu, where algal blooms occur frequently, from June to October (Fig. 10j-k). In particular, consistent with a previous study (Duan et al., 2017), $a_{p h}(443)$ showed an obvious peak in Lake Chaohu in February, which was not observed in Lake Taihu and Lake Hongze. The main reason for this phenomenon is the increase of diatoms, which has higher growth-rate than other algae at low temperatures (below $15^{\circ} \mathrm{C}$ ) (Deng et al., 2007). In contrast, $a_{p h}(443)$ in Lake Hongze presented a regular trend and exhibited low variability through the whole year (Fig. 101). Overall, the optical complexity of Lake Chaohu, Lake Taihu and Lake Hongze was mainly determined by NAP and phytoplankton variations at $443 \mathrm{~nm}$, but variability of $a_{d}(443)$ exceeded that of $a_{p h}(443)$.

\subsection{Extension of QAA-75OE to other lakes in the LYHR basin}

\subsubsection{Algorithm performance}

Performance of QAA-750E was assessed using 17 field measured data in four small lakes (Lake Longgan, Lake Huangda, Lake Gaoyou and Lake Bo) in the LYHR basin. Given the lack of concurrent satellite 

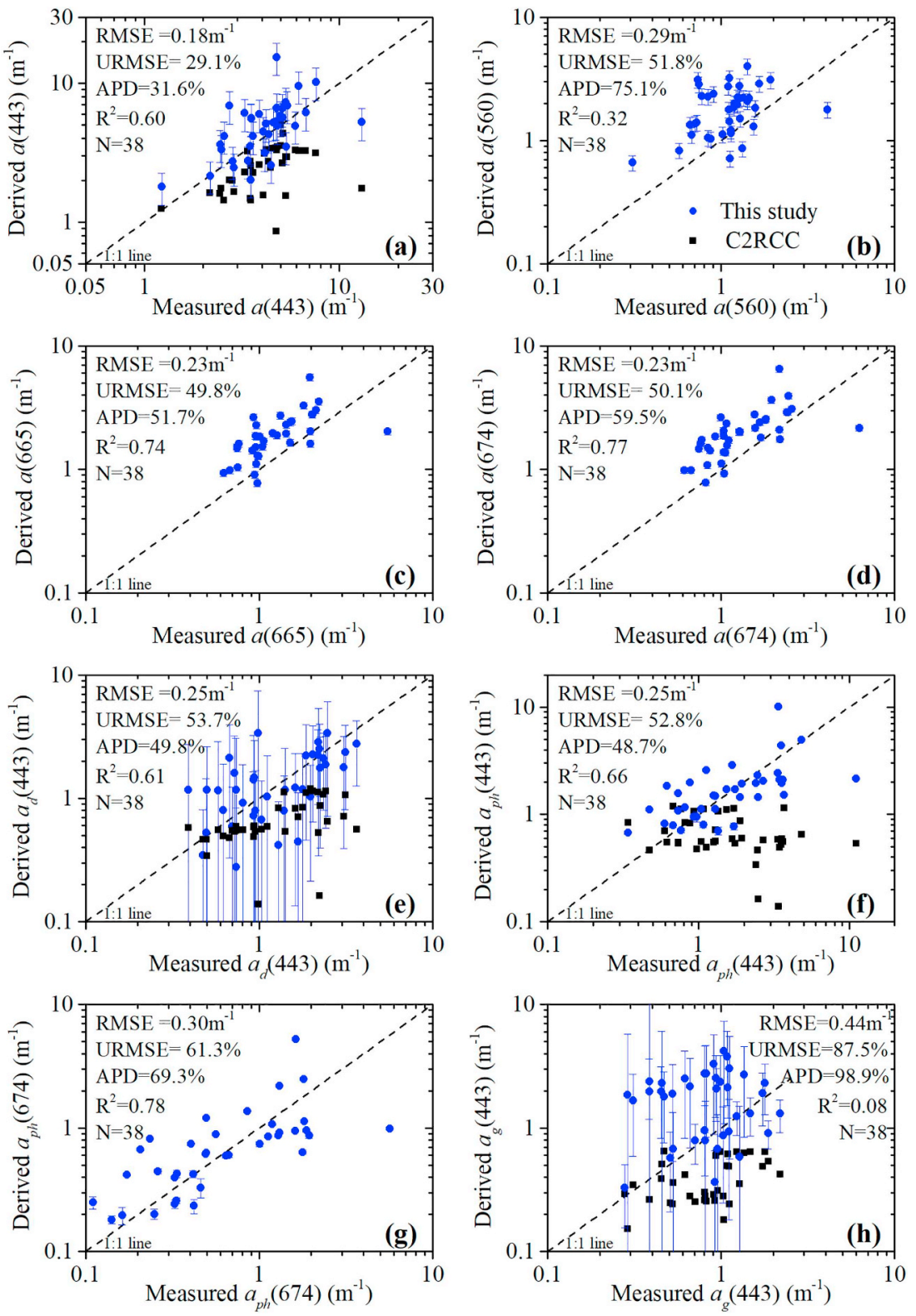

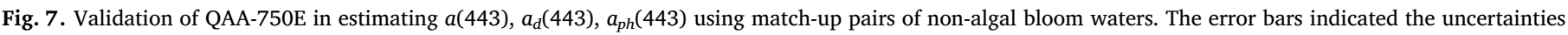
associated to IOPs caused by error propagation in the proposed algorithm. The black squares represent the corresponding results of C2RCC.

and field data on the same day, images within 2 days before and after the field measurements (October 20-24, 2017) were used for additional independent algorithm validation. The mean values of the two images were used to compare with the field measurements only when the retrieved $a(443)$ from the two images agreed to $\pm 50 \%$ around the mean values. The algorithm performed well in estimating $a(443)$ and $a_{d}(443)$ with APD of $13.7 \%\left(\right.$ RMSE $=0.08 \mathrm{~m}^{-1}$, URMSE $=18.4 \%, \mathrm{R}^{2}=0.46$, Fig. 11a) and $25.1 \%$ (RMSE $=0.14 \mathrm{~m}^{-1}$, URMSE $=32.6 \%, \mathrm{R}^{2}=0.71$, Fig. 11b) over lakes in the LYHR basin, respectively. $a_{p h}(443)$ had relatively high uncertainties in statistical measures (RMSE $=0.13 \mathrm{~m}^{-1}$, URMSE $=30.4 \%$, APD $=29.9 \%, R^{2}=0.53$, Fig. 11c).

The algorithm was further applied to estimate the concentrations of Chl $a$ and SPM. $a_{p h}(674)$ derived from QAA-750E had good relationship with field Chla $\left(\right.$ Chl $a=57.41 a_{p h}(675)^{1.33}, \quad \mathrm{R}^{2}=0.89$, $\left.\mathrm{RMSE}=8.54 \mathrm{mg} / \mathrm{m}^{3}, \mathrm{~N}=270\right)$. QAA-750E derived $a_{p}(443)$ had good relationship with field SPM $\left(\mathrm{SPM}=7.47 a_{p}(443)^{1.45}, \quad \mathrm{R}^{2}=0.74\right.$, $\mathrm{RMSE}=17.19 \mathrm{~g} / \mathrm{m}^{3}, \mathrm{~N}=270$ ). The validation results using the field dataset in LYHR showed that Chla (URMSE $=37.0 \%$, APD $=34.5 \%$, $\mathrm{R}^{2}=0.58$, Fig. $11 \mathrm{~d}$ ) and SPM (URMSE $=27.6 \%$, APD $=24.5 \%$, and
$\mathrm{R}^{2}=0.71$, Fig. 11e) can be derived with acceptable performance. Note that overestimation of $a_{g}(443)$ (RMSE $=0.17 \mathrm{~m}^{-1}$, URMSE $=38.3 \%$, $\mathrm{APD}=38.7 \%, \mathrm{R}^{2}=0.78$ ) was observed (Fig. 11f) due to error propagation and low budget of CDOM in total absorption.

\subsubsection{Spatial and seasonal distribution of OACs in $L Y H R$}

Chla, SPM and CDOM (represented by $a_{g}(443)$ ) of lakes in the LYHR basin, that are presented in Fig. 12, showed distinct seasonal and spatial distribution. Generally, Chla was higher in summer and autumn than that in spring and winter in these lakes (Fig. 12a-d). In spring, the western part of Lake Chaohu and northern part of Lake Taihu had high Chla value, which showed similar pattern to $a_{p h}(443)$ (Fig. 12a). Lake Chaohu and Lake Taihu had obviously higher Chla in summer and autumn due to high frequency of algal bloom (Fig. 12b-c). Nearly half part of Lake Poyang is macrophyte zone, and water level changes frequently in a year (Liu et al., 2015). Chla of Lake Poyang was lower than Lake Chaohu and Lake Taihu; and was relatively higher in summer and autumn than spring and winter.

SPM showed large spatial and seasonal variations because of the 


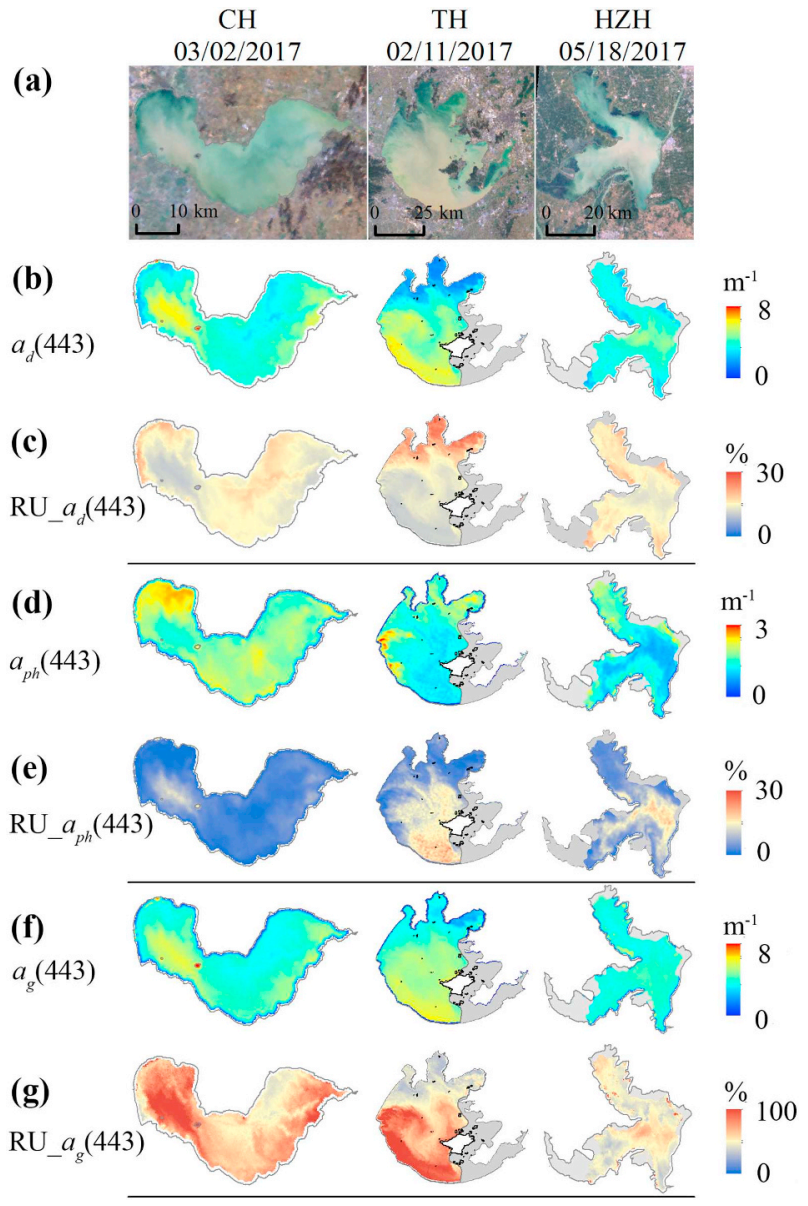

Fig. 8. Examples of derived IOPs and associated uncertainties of Lake Chaohu (Mar 2, 2017), Lake Taihu (Feb 11, 2017), and Lake Hongze (May 18, 2017): (a) RGB images (R: Band 10, G: Band 6, B: Band 3), (b) $a_{d}(443)$, (c) the relative uncertainty (RU) of $a_{d}(443)$, (d) $a_{p h}$ (443), (e) RU of $a_{p h}$ (443), (f) $a_{g}(443)$, and (g) RU of $a_{g}(443)$.

occurrence of algal blooms or sediment resuspension at different lakes (Fig. 12e-h). The high SPM in open water and several bays of Lake Taihu in summer and autumn was mainly caused by the high content of algae in the water column. On the other hand, similar with previous studies, high SPM was observed in spring and winter in open water and southwestern part of Lake Taihu (Shi et al., 2015), and several small lakes (Lake Shijiu, Lake Nanyi and Lake Huangda) (Hou et al., 2017) (Fig. 12e, h). SPM was high in the central and southern parts of Lake Hongze, and was highest in summer, lowest in spring, mainly caused by river discharge, wind and sand dredging activity (Cao et al., 2017). In Lake Poyang, SPM did not exhibit large spatial and seasonal variations, and was relatively higher in autumn. $a_{g}(443)$ showed less spatial and seasonal variations than NAP and phytoplankton, and had lower average value in winter than other seasons (Fig. 12i-1).

\section{Discussion}

\subsection{Factors interfering the IOP inversions}

\subsubsection{Inversion model parameterization}

An objective of QAA-750E is to estimate, beside retrieving the total absorption and backscattering coefficients, the absorption coefficient of each component $\left(a_{d}, a_{p h}\right.$, and $a_{g}$ ) in turbid and eutrophic lakes. NAP (contribution of $a_{d}(443)$ to $a_{n w}(443) \sim 50 \%$ ) and phytoplankton (contribution of $a_{p h}(443) \sim 30 \%$ ) dominated $a_{n w}(443)$ in these waters. Note, however, that the empirical formulas and assumptions of parameters in the proposed algorithm introduce uncertainties to derived IOPs.

In step 2 (Table 3 ), the polynomial parameters relating $u(\lambda)$ and $r_{r s}(\lambda)\left(g_{0}\right.$ and $\left.g_{1}\right)$ are assumed to be constant. The values are 1$) g_{G o r}$ : $\mathrm{g}_{0}=0.0949$ and $\mathrm{g}_{1}=0.0794$ for oceanic Case 1 waters (Gordon et al., 1988); 2) g gee: Lee et al. (1999) suggested $g_{0}$ of 0.084 and $g_{1}$ of 0.17 for higher scattering coastal waters (Lee et al., 2002); 3) $g_{Q A A}$ (Lee et al., 2002): $g_{0}=0.0895$, and $g_{1}=0.1247$, which is the average $g_{0}$ and $g_{1}$ value of $g_{\text {Gor }}$ and $g_{\text {Leee }}$, was used in the three versions of QAA (v4-6). In this study, changing $\mathrm{g}_{\mathrm{QAA}}$ to $\mathrm{g}_{\mathrm{Lee}}$ slightly improved the performance of IOP estimation (APD of $a(443)$ decreasing $\sim 3 \%$ ). In addition, Brando et al. (2012) reported that using $g_{\text {Lee }}$ was much better than $g_{G o r}$ and $\mathrm{g}_{\mathrm{QAA}}$ for retrieving $a(440)$ and $b_{b p}(555)$ for optically complex waters in Fitzroy Estuary and Keppel Bay in Australia.

The assumption of $a(750)$ was based on the measured absorption coefficients at $750 \mathrm{~nm}$ with mean $\Delta a(750)\left(=a(750)-a_{w}(750)\right)$ value of $0.02 \mathrm{~m}^{-1}$. T-mode (transmittance) of $a_{p}(\lambda)$ measurements has uncertainties associated with the unknown level of absorption in the NIR range due to the unknown quantity of scattered loss by the filter with imbedded particles compared to the blank filter (IOCCG, 2018). Previous studies showed that $a_{p}$ in the near-infrared spectral region can reach to values similar to the NIR absorption of pure water in river samples (Röttgers et al., 2014), which had high $a_{d}^{*}(650)$ $\left(0.018 \pm 0.001 \mathrm{~m}^{2} / \mathrm{g}\right)$ and $a_{d}^{*}(750)\left(0.014 \pm 0.001 \mathrm{~m}^{2} / \mathrm{g}\right)$. If the concentration of SPM equals $100 \mathrm{~g} / \mathrm{m}^{3}$, mean $a_{d}(750)$ would be $1.4 \mathrm{~m}^{-1}$ in the river samples in Röttgers et al. (2014). In order to understand the uncertainties introduced from the assumption of $\Delta a(750)$, effects of variations of $\Delta a(750)$ on the RU of IOPs were analyzed using the field-measured datasets (Fig. 13). It indicated that the RU values of $a(443), b_{b p}(560), a_{d}(443)$, and $a_{p h}(443)$ were not sensitive to variation $\Delta a\left(\lambda_{0}\right)$ ranging from 0 to $0.2 \mathrm{~m}^{-1}$, but had larger variations of $\mathrm{RU}$ $(>10 \%)$ when $\Delta a\left(\lambda_{0}\right)>0.5 \mathrm{~m}^{-1}$.

The power-law exponent of $b_{b p}(\lambda)(\mathrm{Y})$ is related to the particle size and composition, and high value of $\mathrm{Y}$ indicates more contribution of small particles in the backscattering coefficients (Aurin and Dierssen, 2012; Babin et al., 2003; Morel and Gentili, 1991). Y affects the derivation of $b_{b}(\lambda)$ and $a(\lambda)$ in the non-reference wavelengths, but had second-order importance in deriving IOPs (Lee et al., 2002). Previous studies showed that QAA-derived $a(\lambda)$ and $b_{b}(\lambda)$ is insensitive to variations of Y (Aurin and Dierssen, 2012; Lee et al., 2009), especially in the spectral range between 490 and $670 \mathrm{~nm}$ (Zheng et al., 2014). For instance, if $r_{r s}(443) / r_{r s}(560)=0.6,50 \%$ variation of $r_{r s}(443) / r_{r s}(560)$ would lead to variation of $\mathrm{Y}<34 \%$, and variation of $b_{b p}(560)<17 \%$ in this study. In QAA-v5 and QAA-v6, $\mathrm{Y}$ was derived using the function of $r_{r s}(443) / r_{r s}(555)$; However, the estimated Y values using equation in QAA (mean value 0.7 ) were obvious lower than the field measured $Y$ (mean value 1.9) in Lake Taihu in 2008 (LT2008) (Duan et al., 2012; Ma et al., 2008). Besides, the measured Y correlated poorly with $r_{r s}$ in the LT2008 data, leading to failure in building a new equation using field measured $\mathrm{Y}$ and $r_{r s}$. Therefore, the new empirical function of $\mathrm{Y}$ in the proposed model was tuned using an Ecolight simulation data set due to the poor correlation between measured $\mathrm{Y}$ and $r_{r s}$. Even though QAA750E-derived $\mathrm{Y}$ did not correlate well with measured $\mathrm{Y}\left(\mathrm{R}^{2}=0.2\right.$, scattering plot not shown), QAA750E-derived $\mathrm{Y}$ and measured $\mathrm{Y}$ had a comparable range and mean value (Fig. 14a). QAA750E-derived $b_{b p}(\lambda)$ showed good correlation $\left(\mathrm{R}^{2}>0.85\right.$, RMSE $<0.37 \mathrm{~m}^{-1}$, APD $<$ $20.75 \%)$ with measured $b_{b p}(\lambda)$ at 443,560 , and $665 \mathrm{~nm}$ in LT2008 dataset, but had slight overestimation in large $b_{b p}(\lambda)$ value (Fig. 14b). Note that uncertainties may also exist in the $b_{b p}(\lambda)$ measured using Hydroscat- 6 instrument in turbid waters with high scattering (Doxaran et al., 2016).

Given that few measurements of $Y$ are available and the fact that the way $\mathrm{Y}$ varies remains unclear (Lee et al., 2002), $\Delta \mathrm{Y}$ was set as 0.5 according to the NOMAD dataset (NASA bio-Optical Marine Algorithm Data set) $(\mathrm{Y}=1.25 \pm 0.46)$ in Lee et al. (2010b). $\Delta \mathrm{Y}=0.5$ was also used in CDOM-dominated, mineral-rich coastal and estuarine waters $(\mathrm{Y}=0.23 \pm 0.18$, ranging from -0.22 to 0.69 ) (Aurin et al., 2010; 

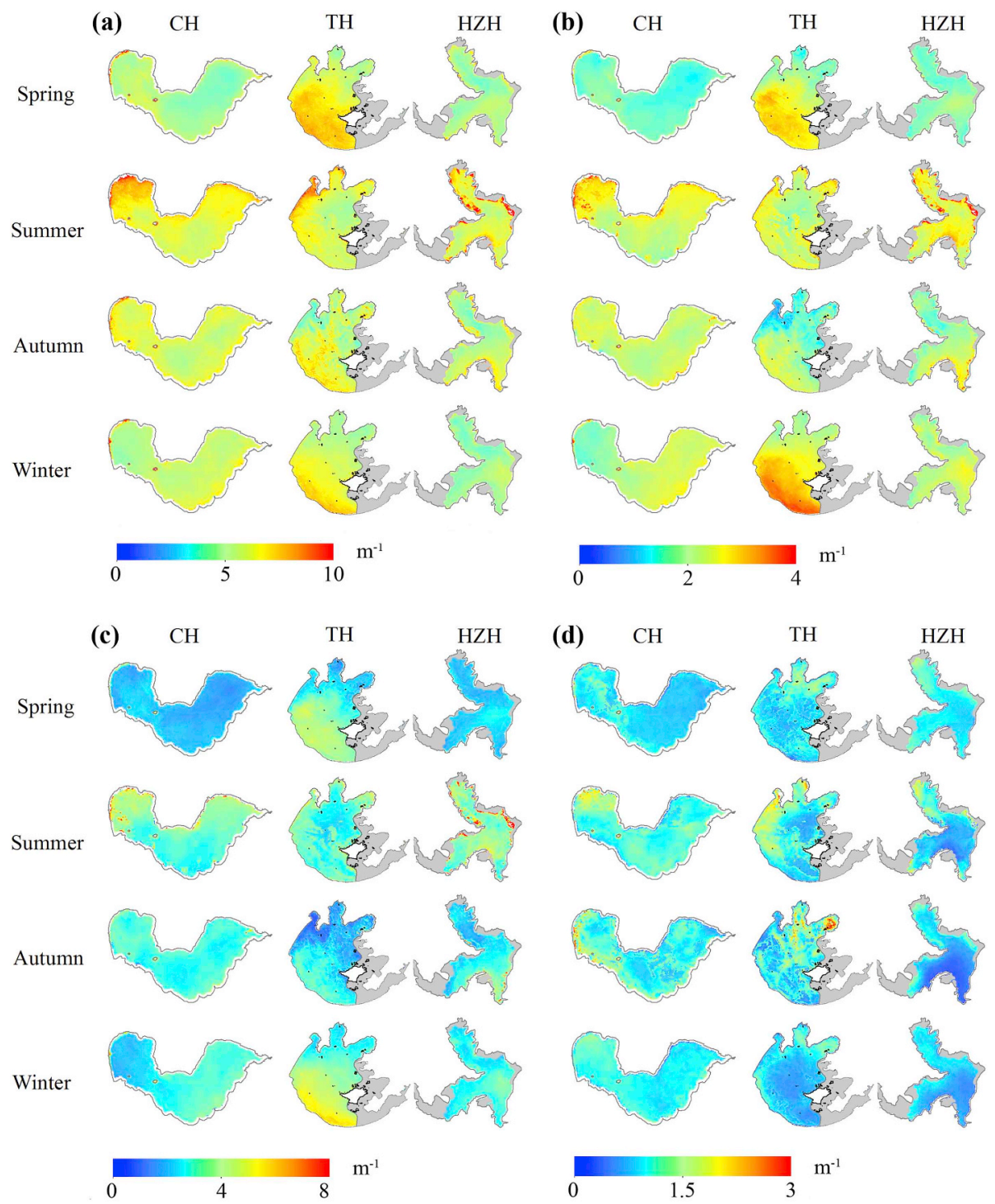

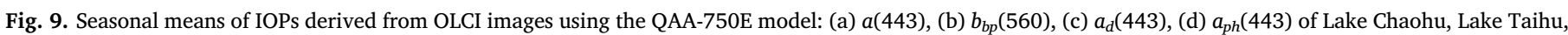
and Lake Hongze from Jan 1, 2017 to Dec 31, 2017. Note that the grey colors in Lake Taihu and Lake Hongze represent aquatic vegetation area.

Aurin and Dierssen, 2012). Besides, Y had a large range (from 0.25 to 2.5) in Arctic and lower-latitude waters (Zheng et al., 2014). The $r_{r s}$ estimated $Y$ ranged from 0.41 to 2.23 with mean value of $1.59 \pm 0.25$ in this study, and thus $\Delta \mathrm{Y}$ was also set to be 0.5 according to Lee et al. (2010b), and Aurin and Dierssen (2012). Moreover, effects of variations of $\Delta \mathrm{Y}$ (ranging from 0.1 to 1.0 ) on the RU of IOPs indicated that RU values of $a(443), b_{b p}(560), a_{d}(443)$, and $a_{p h}(443)$ increased with increasing $\Delta \mathrm{Y}$ (Fig. 13). The mean RU of $a(443)$ was about $25 \%$, when $\Delta \mathrm{Y}=0.5$, and $\Delta a\left(\lambda_{0}\right)=0.2 \mathrm{~m}^{-1}$. Compared with the RU values of $b_{b p}(560), a_{d}(443)$, and $a_{p h}(443)$, RU of $a(443)$ was more sensitive to the variation of $\Delta \mathrm{Y}$.

The current algorithm is not capable of determining the spectrum of $a_{p h}(\lambda)$ effectively. Phytoplankton absorption coefficients at two bands ( $443 \mathrm{~nm}$ and $674 \mathrm{~nm}$ ) were estimated using $a_{n w}$ in the red band to decreasing the influence of optical variations in the proposed algorithm. Variations of phytoplankton absorption, due to phytoplankton groups and pigment composition, need to be considered in the further studying of retrieving spectrum of phytoplankton absorption in optically complex lakes.

\subsubsection{Error propagation}

As in most QAA and QAA-based algorithms, the errors in the derived $a(\lambda), b_{b p}(\lambda), a_{d}(\lambda)$, and $a_{p h}(\lambda)$ propagate to the next steps in this stepby-step process (Lee et al., 2010b; Zhu et al., 2011). One advantage is that $a_{p h}(443)$ and $a_{p h}(674)$ had low uncertainties, resulting from the usage of $a(665)$ and $a(674)$, which had low error propagation errors, derived in the previous steps. In the proposed algorithm, if the fieldmeasured $a(\lambda)$ were set as the input parameters of part II, the APD of $a_{p h}(\lambda)$ would reduce by $\sim 15 \%$. If the average relative error was larger than $20 \%$ in $a(443)$ estimation or $30 \%$ in $a_{d}(443)$, the accuracy of $a_{g}(443)$ decreased dramatically because of the subtraction of the two former terms in the derivation of the latter. The high uncertainties of $a_{g}(443)$ also caused by low contribution $(\sim 19 \%$ at $443 \mathrm{~nm})$ of CDOM to total absorption. A previous study also indicated that high-concentration Chla or sediments might lead to large uncertainty in $a_{g}(443)$ estimation (Zhu et al., 2013). Further research should be conducted to evaluate CDOM in turbid lakes with large amounts of NAP.

\subsubsection{Measurement uncertainties}

The uncertainties in input field measured or satellite-derived $R_{r s}(\lambda)$ can also affect the performance of IOP inversion models (Binding et al., 2008; Zheng and Stramski, 2013). In measurement of $R_{r s}(\lambda)$ using above-water approach, water-leaving radiance $\left(L_{w}(\lambda)\right)$ is derived by correcting the measured above-water upwelling radiance using a 

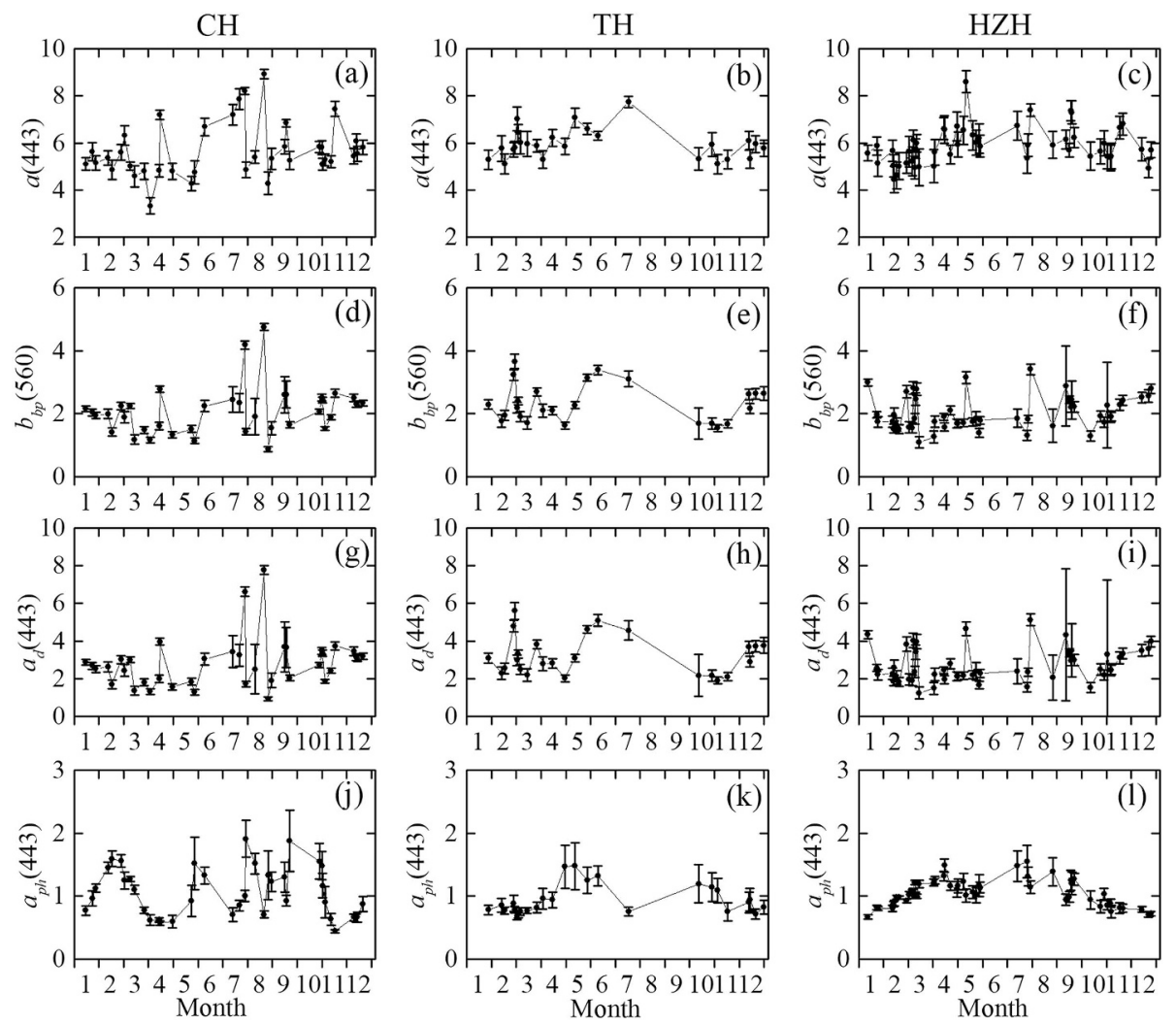

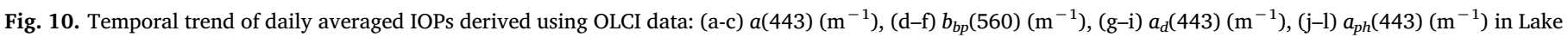
Chaohu, Lake Taihu, and Lake Hongze from Jan 1, 2017 to Dec 31, 2017, respectively.
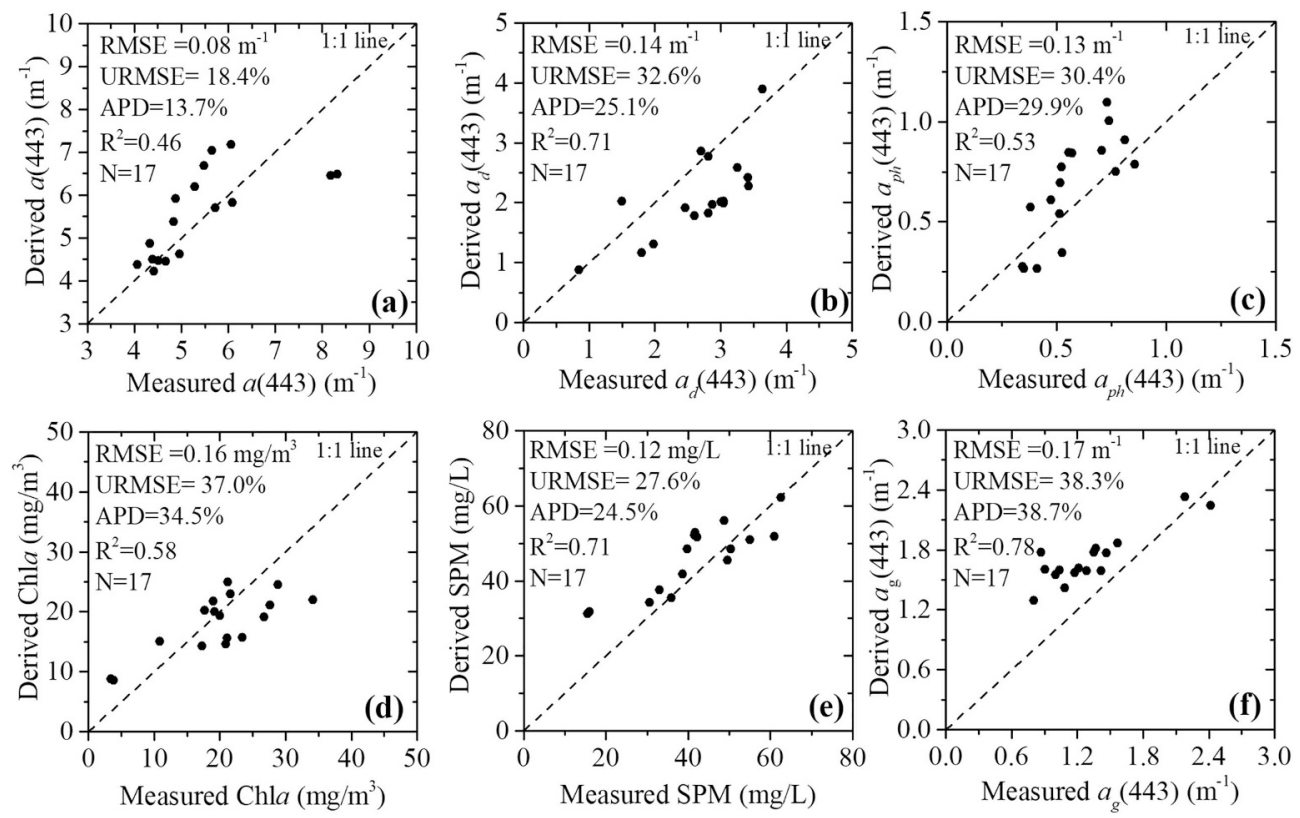

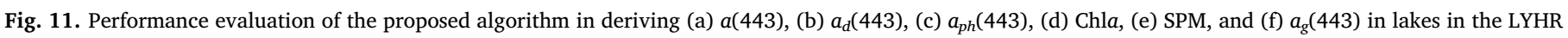
basin. The Dashed line is the 1:1 reference line.

reflectance ratio $(\rho)$, which depends on sky conditions, wind speed, solar zenith angle (Mobley, 1999), sky polarization (Mobley, 2015), and wavelength (Lee et al., 2010a). According to the look-up table of Mobley (1999) and measurement conditions, $\rho=0.028$ was used in this study. Note that changing of $\rho$ from 0.01 to 0.05 would lead to mean coefficient of variance (CV) value of $R_{r s} \sim 50 \%$ at the range of $400-800 \mathrm{~nm}$.
For OLCI-derived $R_{r s}$, C2RCC had obvious overcorrection of $R_{r s}$, and nearly constant value of $R_{r s}(443) / R_{r s}(560)$ ( $\left.~ 0.42\right)$, which is consistent with the study of Bi et al. (2018) in Lake Taihu and Lake Hongze. The neural network (NN) model in C2RCC was trained using the data mostly collected from European waters. In addition, atmospheric correction using both 6S model and C2RCC did not perform well in waters with algal scums or floating blooms, which has high signal in the NIR or 

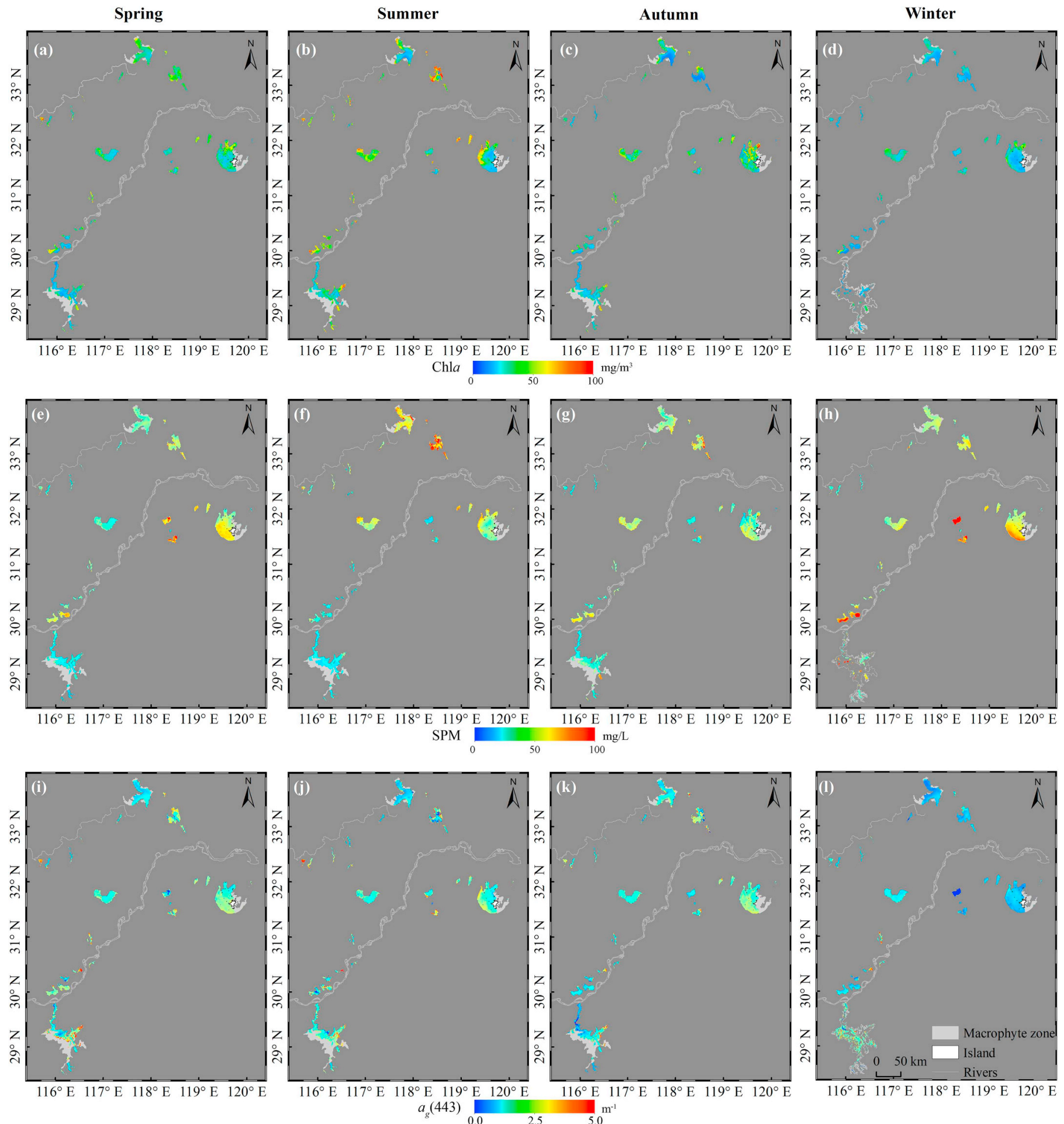

Fig. 12. Seasonal average values of: (a-d) Chla $\left(\mathrm{mg} / \mathrm{m}^{3}\right)$, (e-h) SPM (mg/L), and (i-l) $a_{g}(443)\left(\mathrm{m}^{-1}\right)$ of the lakes in the LYHR basin from Jan 1,2017 to Dec $31,2017$. Note that the aquatic macrophyte zone is showed in light grey, and the blank area of Lake Poyang $(\mathrm{d}, \mathrm{h}, \mathrm{i})$ was caused by the decrease of water level in winter.

SWIR bands. Therefore, the algal blooms pixels were masked in the estimation of IOPs.

Filter-pad methods of $a_{p}(\lambda)$ measurements can be ranked in descending order of superiority as follows: IS (inside an integrating sphere), $\mathrm{T}-\mathrm{R}$ (transmittance reflectance), and $\mathrm{T}$ (transmittance) (Stramski et al., 2015). It is noticeable that T method had large uncertainties in waters with extreme high NIR absorption (Röttgers et al., 2014), and appropriate path-length amplification formula should also be used in the T method (Stramski et al., 2015). The IS method performs better with the beneficial of overall high accuracy and simple protocol of measurements (Röttgers and Gehnke, 2012).

Overall, the retrieved IOPs rely on accuracy of $R_{r s}$ and measured IOPs directly, indicating that improved atmospheric correction and measurement of IOPs and apparent optical properties (AOPs) with high accuracy is necessary. In addition, satellite-to-in situ analysis provided only a general assess of algorithm accuracy (Bailey and Werdell, 2006; Werdell et al., 2018), and error propagation analysis in this study assessed the uncertainties introduced by the model itself. The quantified 

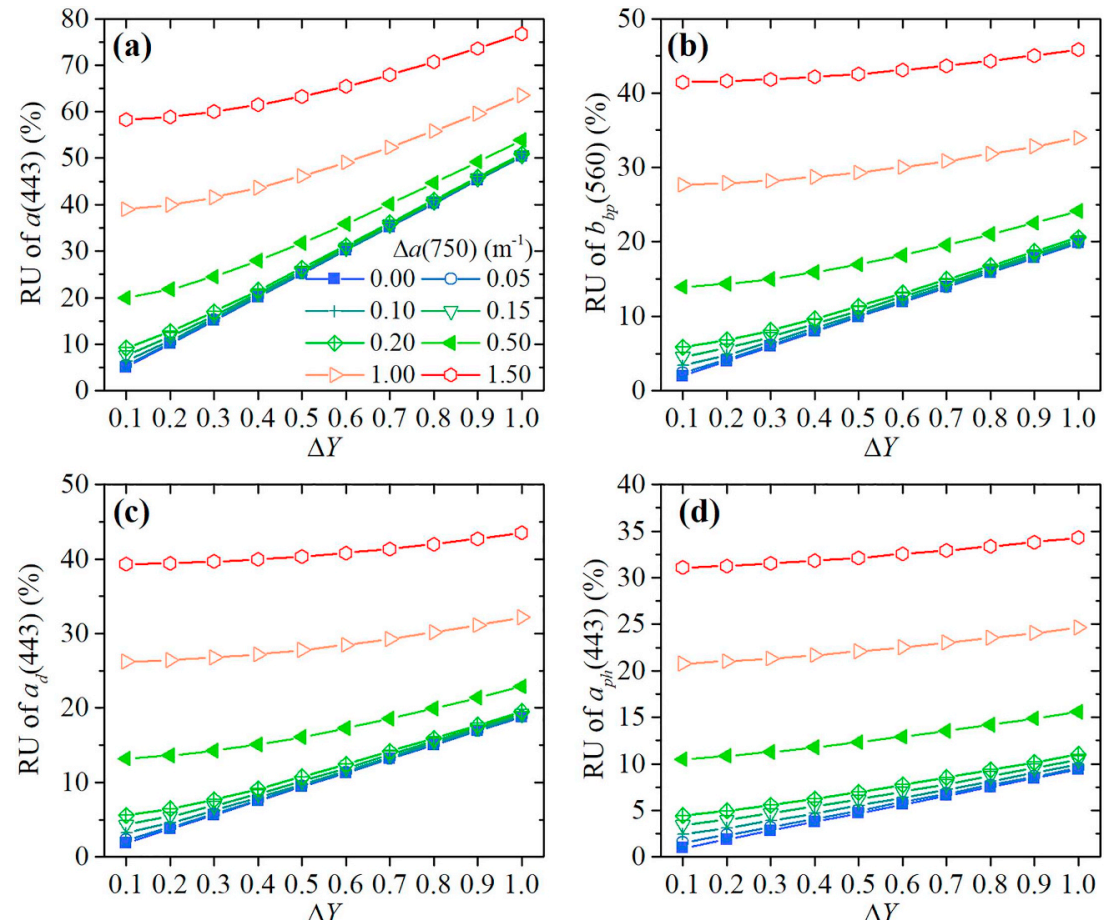

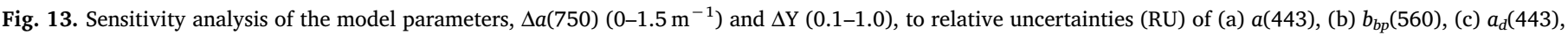
and (d) $a_{p h}$ (443).

uncertainties from field measurement, acquisition and preprocessing of satellite imagery should be collectively considered to adequately resolve variability in time or space, but it is difficult to do so in practice (Werdell et al., 2018; Zhu et al., 2013).

\subsection{Optical characteristics of the three large lakes}

Field-measured bio-optical parameters of Lake Chaohu, Lake Taihu and Lake Hongze showed large range and variability (Table 4). Combined with 29 other lakes and coastal waters, these data were divided into three classes (Fig. 15a): (1) Class 1 represents Lake Chaohu, Lake Taihu and Lake Hongze in this study (Nos. 1-3); (2) Class 2 contains 9 lakes in the LYHR (Nos. 4-13, data were acquired from previous studies and field measurements) (Shi et al., 2011); and (3) Class 3 contains 19 lakes and coastal waters around the world (Nos. 14-32, data were acquired from published articles) (Brunelle et al., 2012; Li et al., 2015;
Meler et al., 2017; Meler et al., 2016; Nima et al., 2016; Perez et al., 2011; Perkins et al., 2013; Riddick et al., 2015; Shi et al., 2011; Trochta et al., 2015; Wang et al., 2014; Wang et al., 2005; Ylöstalo et al., 2014). In addition, the NOMAD dataset were also used to make the comparison of optical properties in different oceanic and coastal waters (Werdell and Bailey, 2005).

Characterized using the ternary absorption budget at $443 \mathrm{~nm}$, the optical similarity of Class 1 and Class 2 indicated that the three lakes had similar optical properties with several lakes in the LYHR basin (Class 2), most of which were dominated by $a_{d}$ (Fig. 15b). $a_{p h}(443)$ in Class 1 was slightly higher and had larger variation than those of waters in Class 2 (Fig. 15c); $a_{d}(443)$ and $a_{g}(443)$ of Class 1 waters had similar mean value with those of Class 2 waters (Fig.15d-e). That is to say, the algorithm built using the data in Class 1 can theoretically be used with Class 2. Thus, although the algorithm parameters should be tuned for a particular lake using local data, QAA-750E algorithm can be applied to
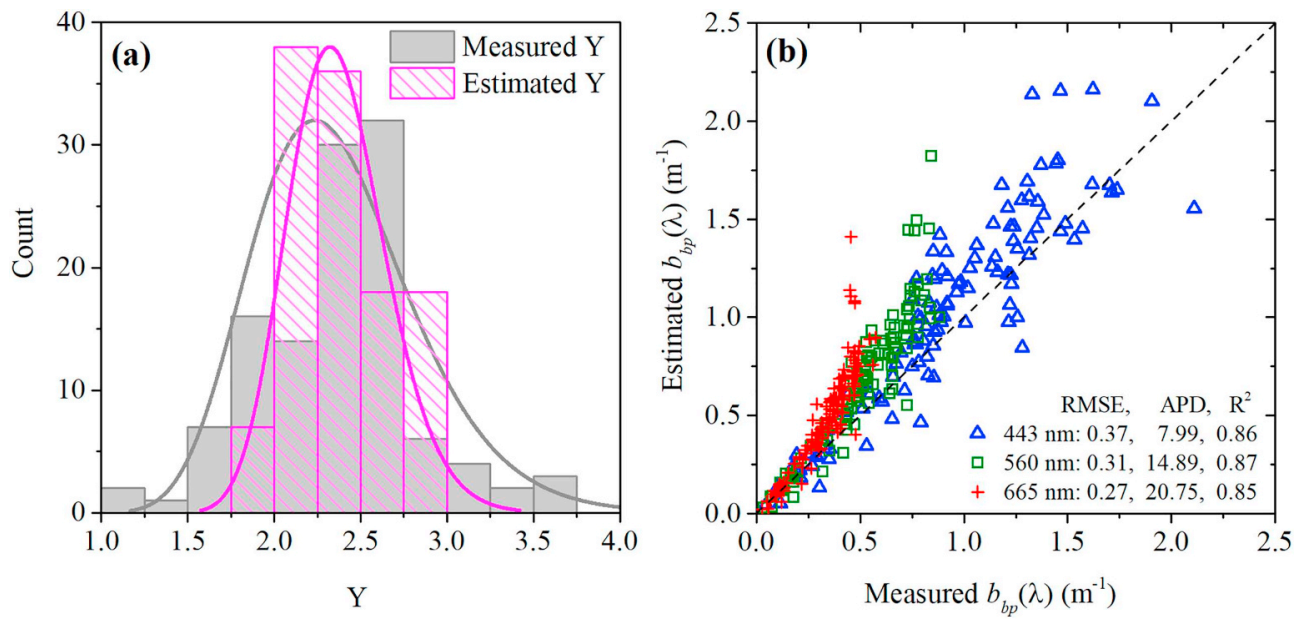

Fig. 14. (a) Histograms of estimated and measured $Y$ with the LT2008 data. (b) Comparison of QAA-750E estimated and measured $b_{b p}(\lambda)$ at $443 \mathrm{~nm}, 560 \mathrm{~nm}$, and 665 nm by using LT2008 data. 

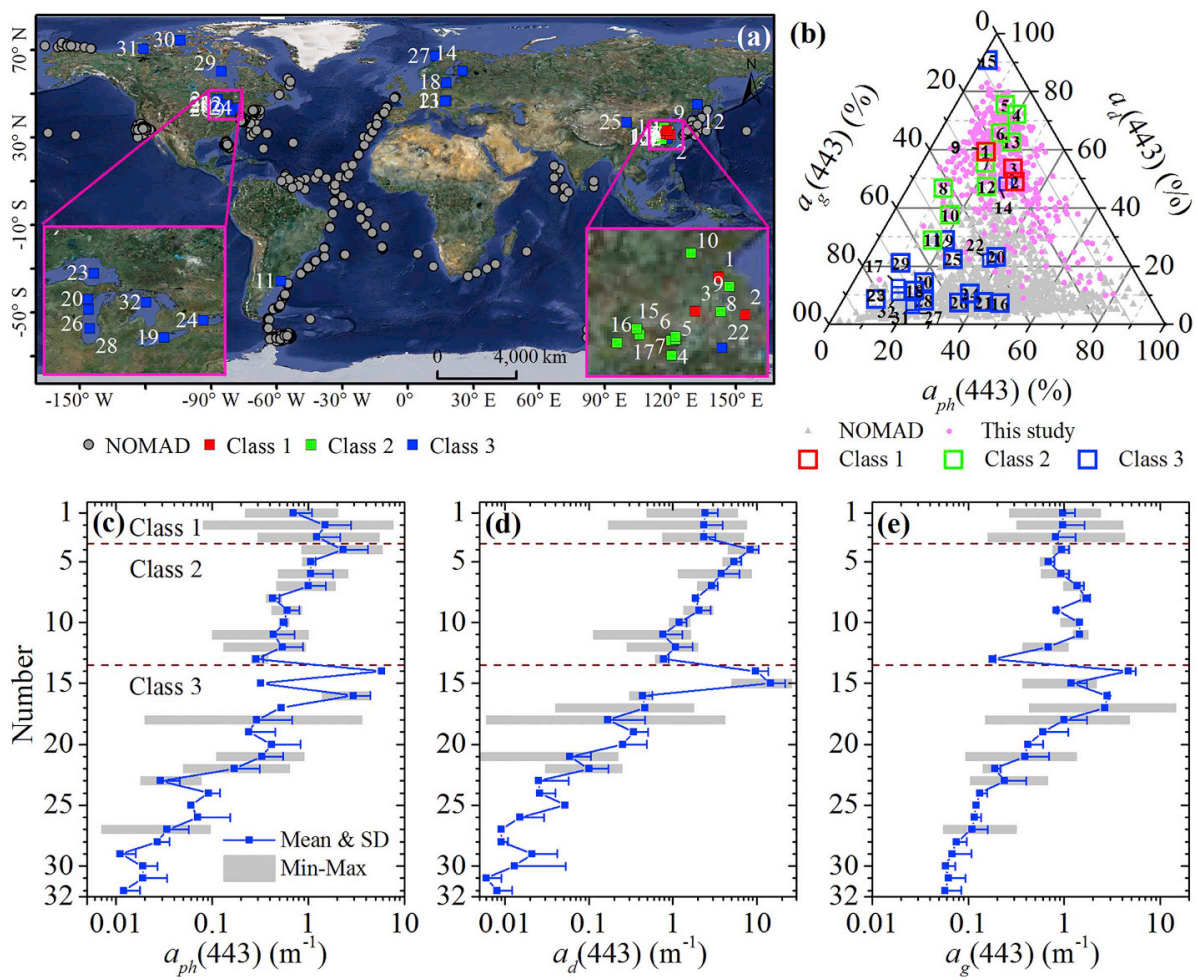

Fig. 15. (a) Location of the lakes and coastal waters and NOMAD stations in the worldwide. Class 1 (Nos. 1-3) represents Lake Hongze, Lake Taihu, and Lake Chaohu in this study, Class 2 (Nos. 4-13) represents lakes in LYHR, and Class 3 (Nos. 14-32) represents lakes and coastal waters in the worldwide. The label of each symbol is the number of the water body. (b) Ternary plot showing the relative contribution of $a_{p h}(443), a_{d}(443)$, and $a_{g}(443)$ to total non-water absorption at $443 \mathrm{~nm}$ in these waters. Plots of (c) $a_{p h}(443)$, (d) $a_{d}(443)$, and (e) $a_{g}(443)$ for waters of Class 1-3. The boundary of the grey column ("MinMax") indicates the minimum and maximum of the data in the previous studies. The solid line is the mean value of each region, and the error bar indicate the standard difference ("Mean \& SD"). These data were acquired from the published articles and field measurement. The number (No.) and name of the waters are as follows: 1 Lake Hongze, 2 Lake Taihu, 3 Lake Chaohu, 4 Lake Longgan, 5 Lake Huangda, 6 Lake Poyang, 7 Lake Gaoyou, 8 Lake Weishan, 9 Lake Bo, 10 Lake Dong, 11 Lake Hong, 12 Lake Liangzi, 13 Lake Shijiu, 14 a highly turbid lake in Argentina, 15 Lake Xingkai, 16 Lake Balaton (Kis-Balaton), 17 Boreal lakes of southern Finland, 18 Coastal of the Baltic sea, 19 Lake Erie (west basin), 20 Lake Michigan (Green Bay), 21 Lake Balaton (main basins), 22 Lake Qiandao, 23 Lake Superior, 24 Lake Ontario, 25 Lake Qinghai, 26 Lake Michigan (off west shore), 27 Norwegian coastal water, 28 Lake Michigan (open waters), 29 Hudson Bay, 30 Canadian Arctic, 31 Amundsen Gulf, 32 Lake Huron. lakes with similar bio-optical properties and variability.

The optical properties among different optical water types usually determine the scope or applicability of an IOP inversion algorithm. Waters in Class 3 and the NOMAD dataset had low total absorption, and were dominated by $a_{p h}(443), a_{g}(443)$ or co-dominated by $a_{p h}-a_{g}$ at $443 \mathrm{~nm}$, with contribution of $a_{d}(443)<40 \%$ (Fig. 15b). The optical diversity between Classes 1-2 and Class 3 and the NOMAD dataset could explain the reason that algorithms built in Class 3 and the NOMAD dataset did not performed well in our dataset. Optical characteristics of the dataset used in this study makes the proposed algorithm suitable to waters with relatively high total absorption and high contribution of NAP and phytoplankton. However, some parameters in the empirical steps of QAA-750E are site-specific. In waters with different optical water types and specific inherent optical properties (SIOPs), local data are still required to optimize or validate the algorithm.

\section{Conclusions}

Based on the general structure of the QAA scheme, an IOP inversion algorithm (QAA-750E) was developed to estimate IOPs in optically complex lakes. In the proposed algorithm, reference wavelength in deriving $a(\lambda)$ was shifted to $750 \mathrm{~nm}$, then, $a_{d}$ and $a_{p h}$ were derived separately using the derived $a(\lambda)$ and $b_{b p}(\lambda)$, respectively. Compared to standard OLCI product, the proposed algorithm performed well in estimating absorption coefficients and backscattering coefficients, and was implemented on Sentinel-3A/OLCI satellite data to map IOPs and associated OACs for lakes in the LYHR basin in 2017. Error propagation analysis provided the uncertainties of derived IOPs on a pixel-by-pixel basis in these lakes. In addition, the IOP variations of the three lakes can represent the optical properties of the lakes in the LYHR basin; however, the spatial and seasonal patterns of IOPs in the three lakes showed different characteristics. Lake Hongze had low variability of IOPs; conversely, Lake Chaohu and Lake Taihu had large variations of $a_{p h}(443)$ in summer and autumn, resulting from frequent occurrence of algal blooms. Moreover, Lake Taihu had high $a_{d}(443)$ in the open area and southwest part of the lake in spring and winter due to wind-driven sediment resuspension. Overall, this approach is suitable for turbid lake waters with similar optical properties and requires local optimization when applied to other waters, as optical water types, error propagation, and field measurements may influence the IOPs inversion. Combined with Envisat/MERIS (MEdium Resolution Imaging Spectrometer) data and the following satellite data (e.g. Sentinel-3B/OLCI), a long term trend of IOP products derived by satellite data would provide a more effective way to explore the changes of water constitutes and light field fluctuations in optically complex lakes.

\section{Acknowledgements}

The authors thank the colleagues from NIGLAS (Jing Li, Dian Wang, Yixuan Zhang, Minqi $\mathrm{Hu}$, and Tianci Qi) for their help with field measurements and data collections. Thanks to Chuanmin $\mathrm{Hu}$ for the comments and suggestions in the early stage of the manuscript. Thanks to Jiqiang Zhao for the help in revising the manuscript. We thank three anonymous reviewers provided extensive comments and suggestions to improve this work. Financial support was provided by the Strategic Priority Research Program of the Chinese Academy of Sciences, China (XDA19040500), National Natural Science Foundation of China (41701416, 41771366, and 41671358), the Natural Science Foundation of Jiangsu Province of China (BK20181509, BK20160049), and NIGLAS project (NIGLAS2017GH03). Acknowledgement for the data support from "Lake-Watershed Science Data Center, National Earth System Science Data Sharing Infrastructure, National Science \& Technology Infrastructure of China. (http://lake.geodata.cn)". 


\section{Appendix A. Error propagation analysis of the proposed model}

On the basis of error propagation theory and analytical expressions of uncertainties (Lee et al., 2010b), uncertainties associated with IOPs derived by QAA-750E were calculated. The following equations present the calculation of $b_{b p}(\lambda), a(\lambda), a_{d}(443)$, and $a_{p h}(443)$ uncertainties. Uncertainties of $b_{b p}(\lambda)$ and $a(\lambda)$ were estimated using the similar equations to Eq. (13b) and Eq. (14) in Lee et al. (2010b). Evaluating the uncertainties of $a\left(\lambda_{0}\right)$ ( $\Delta a$ $\left(\lambda_{0}\right)$ ) and $\mathrm{Y}(\Delta \mathrm{Y})$, which are related to the uncertainty of $r_{r s}(\lambda)$, is difficult. Thus, $\Delta a\left(\lambda_{0}\right)$ was assumed to be $0.02 \mathrm{~m}^{-1}$ based on the statistics of field measured $a(\lambda)$, and $\Delta \mathrm{Y}$ was assumed to be 0.5 according to the previous studies (Aurin et al., 2010; Aurin and Dierssen, 2012; Lee et al., 2010b).

First, two parameters, part $_{1}$ and part $_{2}$, were defined as

$\operatorname{part}_{1}(\lambda)=\mathrm{B}\left(\lambda_{0}\right)\left(\frac{\lambda_{0}}{\lambda}\right)^{\mathrm{Y}} \Delta a\left(\lambda_{0}\right)$

$\operatorname{part}_{2}(\lambda)=\left[\mathrm{B}\left(\lambda_{0}\right) a\left(\lambda_{0}\right)-b_{b \mathrm{w}}\left(\lambda_{0}\right)\right]\left(\frac{\lambda_{0}}{\lambda}\right)^{\mathrm{Y}} \ln \left(\frac{\lambda_{0}}{\lambda}\right) \Delta \mathrm{Y}$

where $\mathrm{B}(\lambda)=\frac{u(\lambda)}{1-u(\lambda)}$

Given that $\Delta a\left(\lambda_{0}\right)$ and $\Delta \mathrm{Y}$ were assumed to be constant, the uncertainties of $b_{b p}(\lambda)$ and $a(\lambda)$ were related to $\mathrm{B}\left(\lambda_{0}\right), \mathrm{Y}$, and $\mathrm{A}(\lambda)$ :

$\Delta b_{b p}(\lambda)=\sqrt{\left(\text { part }_{1}\right)^{2}+\left(\text { part }_{2}\right)^{2}}$

$\Delta a(\lambda)=\sqrt{\left(\mathrm{A}(\lambda) \times \text { part }_{1}\right)^{2}+\left(\mathrm{A}(\lambda) \times \text { part }_{2}\right)^{2}}$

where $\mathrm{A}(\lambda)=\frac{1-u(\lambda)}{u(\lambda)}$

Then, the uncertainty of $a_{d}(443)$ can be derived from the uncertainty of $b_{b p}(\lambda)$,

$\Delta a_{d}(443)=\sqrt{\left(\text { part }_{0}(560) \times \text { part }_{1}(560)\right)^{2}+\left(\text { part }_{0}(560) \times \text { part }_{2}(560)\right)^{2}}$

where

$\operatorname{part}_{0}(\lambda)=1.57 \times\left(\left[\mathrm{B}\left(\lambda_{0}\right) \times a\left(\lambda_{0}\right)-b_{b \mathrm{w}}\left(\lambda_{0}\right)\right]\left(\frac{\lambda_{0}}{\lambda}\right)^{\mathrm{Y}}\right)^{-0.38}$

The uncertainty of $a_{p h}(443)$ (Eq. (A10)) was then derived from the uncertainty of $a_{p h}(674)$ (Eq. (A7)):

$\Delta a_{p h}(674)=\sqrt{\left(\frac{\partial a_{p h}(674)}{\partial a\left(\lambda_{0}\right)}\right)^{2}+\left(\frac{\partial a_{p h}(674)}{\partial \mathrm{Y}}\right)^{2}}$

where

$\frac{\partial a_{p h}(674)}{\partial a\left(\lambda_{0}\right)}=\frac{1}{\varepsilon \times S_{1}-1}\left[\varepsilon \times \mathrm{A}(665) \times \operatorname{part}_{1}(665)-\mathrm{A}(674) \times \operatorname{part}_{1}(674)\right]$

$\frac{\partial a_{p h}(674)}{\partial \mathrm{Y}}=\frac{1}{\varepsilon \times S_{1}-1}\left[\varepsilon \times \mathrm{A}(665) \times \operatorname{part}_{2}(665)-\mathrm{A}(674) \times \operatorname{part}_{2}(674)\right]$

$\Delta a_{p h}(443)=\sqrt{\left(p a r t_{3} \times \frac{\partial a_{p h}(674)}{\partial a\left(\lambda_{0}\right)}\right)^{2}+\left(\operatorname{part}_{3} \times \frac{\partial a_{p h}(674)}{\partial \mathrm{Y}}\right)^{2}}$

where

part $_{3}=1.59 \times a_{p h}(674)^{-0.094}$

The uncertainty of $a_{g}(443)$ was affected by the uncertainty of $a(443), a_{d}(443)$, and $a_{p h}(443)$, and can be calculated by Eq. (A12) based on Eqs. (A4), (A5), and (A10):

$\Delta a_{g}(443)=\sqrt{\left(\frac{\partial a_{g}(443)}{\partial a\left(\lambda_{0}\right)}\right)^{2}+\left(\frac{\partial a_{g}(443)}{\partial \mathrm{Y}}\right)^{2}}$
$=\sqrt{\left(\frac{\partial a(443)}{\partial a\left(\lambda_{0}\right)}-\frac{\partial a_{d}(443)}{\partial a\left(\lambda_{0}\right)}-\frac{\partial a_{p h}(443)}{\partial a\left(\lambda_{0}\right)}\right)^{2}+\left(\frac{\partial a(443)}{\partial \mathrm{Y}}-\frac{\partial a_{d}(443)}{\partial \mathrm{Y}}-\frac{\partial a_{p h}(443)}{\partial \mathrm{Y}}\right)^{2}}$

\section{References}

Aurin, D.A., Dierssen, H.M., 2012. Advantages and limitations of ocean color remote sensing in CDOM-dominated, mineral-rich coastal and estuarine waters. Remote Sens. Environ. 125, 181-197.

Aurin, D., Dierssen, H., Twardowski, M., Roesler, C., 2010. Optical complexity in Long Island sound and implications for coastal ocean color remote sensing. J. Geophys. Res. Oceans 115.

Babin, M., Morel, A., Fournier-Sicre, V., Fell, F., Stramski, D., 2003. Light Scattering Properties of Marine Particles in Coastal and Open Ocean Waters as Related to the
Particle Mass Concentration. vol. 48. pp. 843-859.

Bailey, S.W., Werdell, P.J., 2006. A multi-sensor approach for the on-orbit validation of ocean color satellite data products. Remote Sens. Environ. 102, 12-23.

Bi, S., Li, Y., Wang, Q., Lyu, H., Liu, G., Zheng, Z., Du, C., Mu, M., Xu, J., Lei, S., 2018. Inland water atmospheric correction based on turbidity classification using OLCI and SLSTR synergistic observations. Remote Sens. 10, 1002.

Binding, C., Jerome, J., Bukata, R., Booty, W., 2008. Spectral absorption properties of dissolved and particulate matter in Lake Erie. Remote Sens. Environ. 112, 1702-1711.

Brando, V.E., Dekker, A.G., Park, Y.J., Schroeder, T., 2012. Adaptive semianalytical inversion of ocean color radiometry in optically complex waters. Appl. Opt. 51, 
2808-2833.

Brockmann, C., Doerffer, R., Peters, M., Kerstin, S., Embacher, S., Ruescas, A., 2016. Evolution of the C2RCC neural network for sentinel 2 and 3 for the retrieval of ocean colour products in normal and extreme optically complex waters. In: Living Planet Symposium, pp. 54.

Brunelle, C.B., Larouche, P., Gosselin, M., 2012. Variability of phytoplankton light absorption in Canadian Arctic seas. J. Geophys. Res. Oceans 117, 1-17.

Burns, P., Nolin, A., 2014. Using atmospherically-corrected Landsat imagery to measure glacier area change in the Cordillera Blanca, Peru from 1987 to 2010. Remote Sens. Environ. 140, 165-178.

Cao, Z., Duan, H., Feng, L., Ma, R., Xue, K., 2017. Climate- and human-induced changes in suspended particulate matter over Lake Hongze on short and long timescales. Remote Sens. Environ. 192, 98-113.

Carder, K.L., Chen, F., Lee, Z., Hawes, S., Kamykowski, D., 1999. Semianalytic moderateresolution imaging spectrometer algorithms for chlorophyll a and absorption with bio-optical domains based on nitrate-depletion temperatures. J. Geophys. Res. Oceans 104, 5403-5421.

Cleveland, J.S., Weidemann, A.D., 1993. Quantifying absorption by aquatic particles: a multiple scattering correction for glass-fiber filters. Limnol. Oceanogr. 38, 1321-1327.

Deng, D., Xie, P., Zhou, Q., Yang, H., Guo, L., 2007. Studies on temporal and spatial variations of phytoplankton in Lake Chaohu. J. Integr. Plant Biol. 49, 409-418.

Doerffer, R., Schiller, H., 2007. The MERIS case 2 water algorithm. Int. J. Remote Sens. $28,517-535$.

Dong, Q., Shang, S., Lee, Z., 2013. An algorithm to retrieve absorption coefficient of chromophoric dissolved organic matter from ocean color. Remote Sens. Environ. 128, 259-267.

Doxaran, D., Leymarie, E., Nechad, B., Dogliotti, A., Ruddick, K., Gernez, P., Knaeps, E., 2016. Improved correction methods for field measurements of particulate light backscattering in turbid waters. Opt. Express 24, 3615-3637.

Duan, H., Ma, R., Simis, S.G., Zhang, Y., 2012. Validation of MERIS case-2 water products in Lake Taihu, China. GIScience Remote Sens. 49, 873-894.

Duan, H., Tao, M., Loiselle, S.A., Zhao, W., Cao, Z., Ma, R., Tang, X., 2017. MODIS observations of cyanobacterial risks in a eutrophic lake: implications for long-term safety evaluation in drinking-water source. Water Res. 122, 455-470.

Feng, L., Hu, C., Chen, X., Tian, L., Chen, L., 2012. Human induced turbidity changes in Poyang Lake between 2000 and 2010: observations from MODIS. J. Geophys. Res. Oceans 117.

Ferrari, G.M., Tassan, S., 1999. A method using chemical oxidation to remove light absorption by phytoplankton pigments. J. Phycol. 35, 1090-1098.

Gallegos, C.L., Neale, P.J., 2002. Partitioning spectral absorption in case 2 waters: discrimination of dissolved and particulate components. Appl. Opt. 41, 4220-4233.

Garver, S.A., Siegel, D.A., 1997. Inherent optical property inversion of ocean color spectra and its biogeochemical interpretation: 1. Time series from the Sargasso Sea. J. Geophys. Res.-Atmos. 102, 18607-18625.

Gitelson, A.A., Dall'Olmo, G., Moses, W., Rundquist, D.C., Barrow, T., Fisher, T.R., Gurlin, D., Holz, J., 2008. A simple semi-analytical model for remote estimation of chlorophyll-a in turbid waters: validation. Remote Sens. Environ. 112, 3582-3593.

Gordon, H.R., Brown, O.B., Jacobs, M.M., 1975. Computed relationships between the inherent and apparent optical properties of a flat homogeneous ocean. Appl. Opt. 14, 417-427.

Gordon, H.R., Brown, O.B., Evans, R.H., Brown, J.W., Smith, R.C., Baker, K.S., Clark, D.K., 1988. A semianalytic radiance model of ocean color. J. Geophys. Res.-Atmos. 93, 10909-10924.

Hieronymi, M., Müller, D., Doerffer, R., 2017. The OLCI neural network swarm (ONNS): a bio-geo-optical algorithm for Open Ocean and coastal waters. Front. Mar. Sci. 4.

Hoge, F.E., Lyon, P.E., 2005. New tools for the study of oceanic eddies: satellite derived inherent optical properties. Remote Sens. Environ. 95, 444-452.

Hou, X., Feng, L., Duan, H., Chen, X., Sun, D., Shi, K., 2017. Fifteen-year monitoring of the turbidity dynamics in large lakes and reservoirs in the middle and lower basin of the Yangtze River, China. Remote Sens. Environ. 190, 107-121.

Hu, C., 2009. A novel ocean color index to detect floating algae in the global oceans. Remote Sens. Environ. 113, 2118-2129.

Huang, C., Shi, K., Yang, H., Li, Y., Zhu, A.x., Sun, D., Xu, L., Zou, J., Chen, X., 2015. Satellite observation of hourly dynamic characteristics of algae with Geostationary Ocean Color Imager (GOCI) data in Lake Taihu. Remote Sens. Environ. 159, 278-287.

IOCCG, 2018. Inherent optical property measurements and protocols: Absorption coefficient. In: Neeley, A.R., Mannino, A. (Eds.), IOCCG Ocean Optics and Biogeochemistry Protocols for Satellite Ocean Colour Sensor Validation, Volume 1.0. IOCCG, Dartmouth, NS, Canada.

Jiang, G., Ma, R., Loiselle, S.A., Duan, H., 2012. Optical approaches to examining the dynamics of dissolved organic carbon in optically complex inland waters. Environ. Res. Lett. 7, 034014.

Kirk, J.T.O., 1984. Dependence of relationship between inherent and apparent optical properties of water on solar altitude. Limnol. Oceanogr. 29, 350-356.

Kutser, T., Pierson, D.C., Kallio, K.Y., Reinart, A., Sobek, S., 2005. Mapping lake CDOM by satellite remote sensing. Remote Sens. Environ. 94, 535-540.

Le, C., Li, Y., Zha, Y., Sun, D., Yin, B., 2009. Validation of a quasi-analytical algorithm for highly turbid eutrophic water of Meiliang Bay in Taihu Lake, China. IEEE Trans. Geosci. Remote Sens. 47, 2492-2500.

Lee, Z., 2005. Diffuse attenuation coefficient of downwelling irradiance: an evaluation of remote sensing methods. J. Geophys. Res. 110.

Lee, Z., 2014. Update of the quasi-analytical algorithm (QAA_v6). http://www.ioccg.org/ groups/Software_OCA/QAA_v6_2014209.pdf.

Lee, Z., Carder, K.L., Mobley, C.D., Steward, R.G., Patch, J.S., 1999. Hyperspectral remote sensing for shallow waters: 2 . Deriving bottom depths and water properties by optimization. Appl. Opt. 38, 3831-3843.

Lee, Z., Carder, K.L., Arnone, R.A., 2002. Deriving inherent optical properties from water color: a multiband quasi-analytical algorithm for optically deep waters. Appl. Opt. 41, 5755-5772.

Lee, Z., Lubac, B., Werdell, J., Arnone, R., 2009. An update of the quasi-analytical algorithm (QAA_v5). In: IOCCG Software Report.

Lee, Z., Ahn, Y.-H., Mobley, C., Arnone, R., 2010a. Removal of surface-reflected light for the measurement of remote-sensing reflectance from an above-surface platform. Opt. Express 18, 26313-26324.

Lee, Z., Arnone, R., Hu, C., Werdell, P.J., Lubac, B., 2010b. Uncertainties of optical parameters and their propagations in an analytical ocean color inversion algorithm. Appl. Opt. 49, 369-381.

Lee, Z., Lance, V.P., Shang, S., Vaillancourt, R., Freeman, S., Lubac, B., Hargreaves, B.R., Del Castillo, C., Miller, R., Twardowski, M., Wei, G., 2011. An assessment of optical properties and primary production derived from remote sensing in the Southern Ocean (SO GasEx). J. Geophys. Res. 116.

Li, L., Li, L., Song, K., Li, Y., Tedesco, L.P., Shi, K., Li, Z., 2013. An inversion model for deriving inherent optical properties of inland waters: establishment, validation and application. Remote Sens. Environ. 135, 150-166.

Li, S., Song, K., Chen, Z., Zhao, Y., Shao, T., Mu, G., Guan, Y., 2015. Absorption characteristics of particulates and CDOM in spring in the Lake Xingkai. J. Lake Sci. 941-952.

Liu, X., Qian, K., Chen, Y., 2015. Effects of water level fluctuations on phytoplankton in a Changjiang River floodplain Lake (Poyang Lake): implications for dam operations. J. Great Lakes Res. 41, 770-779.

Loisel, H., Stramski, D., 2000. Estimation of the inherent optical properties of natural waters from the irradiance attenuation coefficient and reflectance in the presence of Raman scattering. Appl. Opt. 39, 3001-3011.

Loisel, H., Stramski, D., Dessailly, D., Jamet, C., Li, L., Reynolds, R.A., 2018. An inverse model for estimating the optical absorption and backscattering coefficients of seawater from remote-Sensing reflectance over a broad range of oceanic and coastal marine environments. J. Geophys. Res. Oceans 123, 2141-2171.

Ma, R., Song, Q., Li, G., Pan, D., 2008. Estimation of backscattering probability of Lake Taihu waters. J. Lake Sci. 20, 375-379.

Ma, R., Duan, H., Hu, C., Feng, X., Li, A., Ju, W., Jiang, J., Yang, G., 2010. A half-century of changes in China's lakes: global warming or human influence? Geophys. Res. Lett. 37.

Maritorena, S., Siegel, D.A., 2005. Consistent merging of satellite ocean color data sets using a bio-optical model. Remote Sens. Environ. 94, 429-440.

Meler, J., Ostrowska, M., Stoń-Egiert, J., 2016. Seasonal and spatial variability of phytoplankton and non-algal absorption in the surface layer of the Baltic. Estuar. Coast. Shelf Sci. 180, 123-135.

Meler, J., Ostrowska, M., Ficek, D., Zdun, A., 2017. Light absorption by phytoplankton in the southern Baltic and Pomeranian lakes: mathematical expressions for remote sensing applications. Oceanologia 59, 195-212.

Mishra, S., Mishra, D.R., Lee, Z., Tucker, C.S., 2013. Quantifying cyanobacterial phycocyanin concentration in turbid productive waters: a quasi-analytical approach. Remote Sens. Environ. 133, 141-151.

Mitchell, B.G., 1990. Algorithms for determining the absorption-coefficient of aquatic particulates using the quantitative filter technique (Qft). Proc. SPIE Int. Soc. Opt. Eng. 1302, 137-148.

Mitchell, C., Cunningham, A., 2015. Remote sensing of spatio-temporal relationships between the partitioned absorption coefficients of phytoplankton cells and mineral particles and euphotic zone depths in a partially mixed shelf sea. Remote Sens. Environ. 160, 193-205.

Mitchell, B.G., Kahru, M., Wieland, J., \& Stramska, M. (2003). Determination of spectral absorption coefficients of particles, dissolved material and phytoplankton for discrete water samples. In, In Ocean Optics Protocols for Satellite Ocean Color Sensor Validation; Revision 4; Volume IV: Inherent optical properties: Instruments, characterizations, field measurements and data analysis protocols; Mueller, JL, Fargion, GS, McClain, CR, Eds.; NASA Goddard Space Flight (pp. 39-56): (Citeseer).

Mitchell, C., Cunningham, A., McKee, D., 2014. Remote sensing of particulate absorption coefficients and their biogeochemical interpretation: a case study in the Irish Sea. Remote Sens. Environ. 152, 74-82.

Mobley, C.D., 1999. Estimation of the remote-sensing reflectance from above-surface measurements. Appl. Opt. 38, 7442-7455.

Mobley, C.D., 2015. Polarized reflectance and transmittance properties of windblown sea surfaces. Appl. Opt. 54, 4828-4849.

Moore, T.S., Campbell, J.W., Dowell, M.D., 2009. A class-based approach to characterizing and mapping the uncertainty of the MODIS Ocean chlorophyll product. Remote Sens. Environ. 113, 2424-2430.

Morel, A., Gentili, B., 1991. Diffuse reflectance of oceanic waters: its dependence on Sun angle as influenced by the molecular scattering contribution. Appl. Opt. 30, 4427-4438.

Morel, A., Prieur, L., 1977. Analysis of variations in ocean color1. Limnol. Oceanogr. 22, 709-722.

Mouw, C.B., Chen, H., McKinley, G.A., Effler, S., O'Donnell, D., Perkins, M.G., Strait, C., 2013. Evaluation and optimization of bio-optical inversion algorithms for remote sensing of Lake Superior's optical properties. J. Geophys. Res. Oceans 118, 1696-1714.

Nima, C., Frette, Ø., Hamre, B., Erga, S.R., Chen, Y.-C., Zhao, L., Sørensen, K., Norli, M., Stamnes, K., Stamnes, J.J., 2016. Absorption properties of high-latitude Norwegian coastal water: the impact of CDOM and particulate matter. Estuar. Coast. Shelf Sci. $178,158-167$

Perez, G.L., Llames, M.E., Lagomarsino, L., Zagarese, H., 2011. Seasonal variability of optical properties in a highly turbid lake (Laguna Chascomus, Argentina) 
Photochem. Photobiol. 87, 659-670.

Perkins, M., Effler, S.W., Peng, F., O'Donnell, D.M., Strait, C., 2013. Light-absorbing components in the Great Lakes. J. Great Lakes Res. 39, 123-136.

Pope, R.M., Fry, E.S., 1997. Absorption spectrum $(380-700 \mathrm{~nm})$ of pure water. II. Integrating cavity measurements. Appl. Opt. 36, 8710-8723.

Qi, L., Hu, C., Duan, H., Cannizzaro, J., Ma, R., 2014. A novel MERIS algorithm to derive cyanobacterial phycocyanin pigment concentrations in a eutrophic lake: theoretical basis and practical considerations. Remote Sens. Environ. 154, 298-317.

Qin, N., He, W., Kong, X., Liu, W., He, Q., Yang, B., Ouyang, H., Wang, Q., Xu, F., 2013. Atmospheric partitioning and the air-water exchange of polycyclic aromatic hydrocarbons in a large shallow Chinese lake (Lake Chaohu). Chemosphere 93, 1685-1693.

Qin, P., Simis, S.G., Tilstone, G.H., 2017. Radiometric validation of atmospheric correction for MERIS in the Baltic Sea based on continuous observations from ships and AERONET-OC. Remote Sens. Environ. 200, 263-280.

Riddick, C.A.L., Hunter, P.D., Tyler, A.N., Martinez-Vicente, V., Horváth, H., Kovács, A.W., Vörös, L., Preston, T., Présing, M., 2015. Spatial variability of absorption coefficients over a biogeochemical gradient in a large and optically complex shallow lake. J. Geophys. Res. Oceans 120, 7040-7066.

Röttgers, R., Gehnke, S., 2012. Measurement of light absorption by aquatic particles: improvement of the quantitative filter technique by use of an integrating sphere approach. Appl. Opt. 51, 1336-1351.

Röttgers, R., Dupouy, C., Taylor, B.B., Bracher, A., Woźniak, S.B., 2014. Mass-specific light absorption coefficients of natural aquatic particles in the near-infrared spectral region. Limnol. Oceanogr. 59, 1449-1460.

Ruescas, A.B., Hieronymi, M., Mateo-Garcia, G., Koponen, S., Kallio, K., Camps-Valls, G., 2018. Machine learning regression approaches for colored dissolved organic matter (CDOM) retrieval with S2-MSI and S3-OLCI simulated data. Remote Sens. 10, 786.

Schofield, O., Bergmann, T., Oliver, M.J., Irwin, A., Kirkpatrick, G., Bissett, W.P., Moline, M.A., Orrico, C., 2004. Inversion of spectral absorption in the optically complex coastal waters of the mid-Atlantic bight. J. Geophys. Res. Oceans 109.

Shen, M., Duan, H., Cao, Z., Xue, K., Loiselle, S., Yesou, H., 2017. Determination of the downwelling diffuse attenuation coefficient of lake water with the sentinel-3A OLCI. Remote Sens. 9, 1246.

Shi, Z., Zhang, Y., Liu, M., Yuan, X., Yin, Y., \& Liu, X. (2011). Spectral absorption coef ficients of particulate matter in Lake Donghu, Lake Liangzihu, and Lake Honghu. Resources and Environment in the Yangtze Basin, 736-743.

Shi, K., Zhang, Y., Zhu, G., Liu, X., Zhou, Y., Xu, H., Qin, B., Liu, G., Li, Y., 2015, Longterm remote monitoring of total suspended matter concentration in Lake Taihu using 250m MODIS-aqua data. Remote Sens. Environ. 164, 43-56.

Stanford, B.H., Gordana, L., Giuseppe, Z., Scott, M., 2002. An evaluation of above- and inwater methods for determining water-leaving radiances. J. Atmos. Ocean. Technol. $19,486-515$.

Stramski, D., Reynolds, R.A., Kahru, M., Mitchell, B.G., 1999. Estimation of particulate organic carbon in the ocean from satellite remote sensing. Science 285, 239-242.

Stramski, D., Reynolds, R.A., Kaczmarek, S., Uitz, J., Zheng, G., 2015. Correction of pathlength amplification in the filter-pad technique for measurements of particulate absorption coefficient in the visible spectral region. Appl. Opt. 54, 6763-6782.

Tang, J., Shi, T., Wu, X., Cao, H., Li, X., Hua, R., Tang, F., Yue, Y., 2015. The occurrence and distribution of antibiotics in Lake Chaohu, China: seasonal variation, potential source and risk assessment. Chemosphere 122, 154-161.

Trochta, J.T., Mouw, C.B., Moore, T.S., 2015. Remote sensing of physical cycles in Lake Superior using a spatio-temporal analysis of optical water typologies. Remote Sens. Environ. 171, 149-161.

Vandermeulen, R.A., Arnone, R., Ladner, S., Martinolich, P., 2015. Enhanced satellite remote sensing of coastal waters using spatially improved bio-optical products from SNPP-VIIRS. Remote Sens. Environ. 165, 53-63.

Vantrepotte, V., Loisel, H., Dessailly, D., Mériaux, X., 2012. Optical classification of contrasted coastal waters. Remote Sens, Fnviron, 123, 306-323.
Vermote, E.F., Tanre, D., Deuze, J.L., Herman, M., Morcette, J.J., 1997. Second simulation of the satellite signal in the solar Spectrum, 6S: an overview. IEEE Trans. Geosci. Remote Sens. 35, 675-686.

Wang, X., Li, T., Zhu, J., 2005. Analyzing surface water optical pro per ties of Qinghai Lake. J. Ocean Technol. 50-54.

Wang, M., Zhang, Y., Shi, K., Gao, Y., Liu, G., Jiang, H., 2014. Characteristics of optical absorption coefficients and their differences in typical seasons in Lake Qiandaohu. J. Environ. Sci. 2528-2538.

Werdell, P.J., Bailey, S.W., 2005. An improved in-situ bio-optical data set for ocean color algorithm development and satellite data product validation. Remote Sens. Environ. 98, 122-140.

Werdell, P.J., Franz, B.A., Bailey, S.W., Feldman, G.C., Boss, E., Brando, V.E., Dowell, M., Hirata, T., Lavender, S.J., Lee, Z., Loisel, H., Maritorena, S., Mélin, F., Moore, T.S., Smyth, T.J., Antoine, D., Devred, E., d'Andon, O.H.F., Mangin, A., 2013. Generalized Ocean color inversion model for retrieving marine inherent optical properties. Appl. Opt. 52, 2019-2037.

Werdell, P.J., McKinna, L.I.W., Boss, E., Ackleson, S.G., Craig, S.E., Gregg, W.W., Lee, Z., Maritorena, S., Roesler, C.S., Rousseaux, C.S., Stramski, D., Sullivan, J.M., Twardowski, M.S., Tzortziou, M., Zhang, X., 2018. An overview of approaches and challenges for retrieving marine inherent optical properties from ocean color remote sensing. Prog. Oceanogr. 160, 186-212.

Xue, K., 2016. The Effects of Vertical Distribution of Phytoplankton on Remote Sensing Reflectance in Chaohu Lake. University of Chinese Academy of Sciences.

Xue, K., Zhang, Y., Duan, H., Ma, R., 2017a. Variability of light absorption properties in optically complex inland waters of Lake Chaohu, China. J. Great Lakes Res. 43, 17-31.

Xue, K., Zhang, Y., Ma, R., Duan, H., 2017b. An approach to correct the effects of phytoplankton vertical nonuniform distribution on remote sensing reflectance of cyanobacterial bloom waters. Limnol. Oceanogr. Methods 15, 302-319.

Yang, L., Lei, K., Meng, W., Fu, G., Yan, W., 2013. Temporal and spatial changes in nutrients and chlorophyll- $\alpha$ in a shallow lake, Lake Chaohu, China: an 11-year investigation. J. Environ. Sci. 25, 1117-1123.

Ylöstalo, P., Kallio, K., Seppälä, J., 2014. Absorption properties of in-water constituents and their variation among various lake types in the boreal region. Remote Sens. Environ. 148, 190-205.

Zhang, Y., Zhang, B., Wang, X., Li, J., Feng, S., Zhao, Q., Liu, M., Qin, B., 2007. A study of absorption characteristics of chromophoric dissolved organic matter and particles in Lake Taihu, China. Hydrobiologia 592, 105-120.

Zhang, Y., Ma, R., Duan, H., Loiselle, S.A., Xu, J., Ma, M., 2014. A Novel Algorithm to Estimate Algal Bloom Coverage to Subpixel Resolution in Lake Taihu. IEEE Journal of Selected Topics in Applied Earth Observations and Remote Sensing 7, 3060-3068.

Zheng, G., Stramski, D., 2013. A model based on stacked-constraints approach for partitioning the light absorption coefficient of seawater into phytoplankton and nonphytoplankton components. J. Geophys. Res. Oceans 118, 2155-2174.

Zheng, G., Stramski, D., Reynolds, R.A., 2014. Evaluation of the quasi-analytical algorithm for estimating the inherent optical properties of seawater from ocean color: comparison of Arctic and lower-latitude waters. Remote Sens. Environ. 155, 194-209.

Zheng, G., Stramski, D., DiGiacomo, P.M., 2015. A model for partitioning the light absorption coefficient of natural waters into phytoplankton, nonalgal particulate, and colored dissolved organic components: a case study for the Chesapeake Bay. J, Geophys. Res. Oceans 120, 2601-2621.

Zhu, W., Yu, Q., Tian, Y.Q., Chen, R.F., Gardner, G.B., 2011. Estimation of chromophoric dissolved organic matter in the Mississippi and Atchafalaya river plume regions using above-surface hyperspectral remote sensing. J. Geophys. Res. 116.

Zhu, W., Yu, Q., Tian, Y.Q., 2013. Uncertainty analysis of remote sensing of colored dissolved organic matter: evaluations and comparisons for three rivers in North America. ISPRS J. Photogramm. Remote Sens. 84, 12-22. 